\title{
Plastid genetic engineering in Solanaceae
}

\author{
Jelli Venkatesh • Se Won Park
}

Received: 19 October 2011 / Accepted: 21 February 2012 / Published online: 7 March 2012

(C) The Author(s) 2012. This article is published with open access at Springerlink.com

\begin{abstract}
Plastid genetic engineering has come of age, becoming today an attractive alternative approach for the expression of foreign genes, as it offers several advantages over nuclear transformants. Significant progress has been made in plastid genetic engineering in tobacco and other Solanaceae plants, through the use of improved regeneration procedures and transformation vectors with efficient promoters and untranslated regions. Many genes encoding for industrially important proteins and vaccines, as well as genes conferring important agronomic traits, have been stably integrated and expressed in the plastid genome. Despite these advances, it remains a challenge to achieve marked levels of plastid transgene expression in non-green tissues. In this review, we summarize the basic requirements of plastid genetic engineering and discuss the current status, limitations, and the potential of plastid transformation for expanding future studies relating to Solanaceae plants.
\end{abstract}

Keywords Genetic engineering · Homoplasmic · Plastid · Solanaceae $\cdot$ Transplastome

\section{Introduction}

The family Solanaceae consists of a number of economically important plants, including several major food crops, such as tomato, potato, eggplant, and pepper; ornamental crops, such as petunia; and medicinal crops, such as

\section{Handling Editor: Peter Nick}

J. Venkatesh $\cdot$ S. W. Park $(\square)$

Department of Molecular Biotechnology, Konkuk University,

1 Hwayang-dong, Gwangjin-gu,

Seoul 143-701, Republic of Korea

e-mail: sewpark@konkuk.ac.kr
Withania, Datura, Mandragora, Atropa, and Physalis. The production of Solanaceae crops is constrained by several biotic and abiotic factors. Consequently, genetic engineering of Solanaceae plants has turned into a tool for the improvement of genotypes with increased tolerance to abiotic stresses, pests, and diseases. Some of the Solanaceae crop plants have become the targets of biofortification programs. Additionally, these crops have become bioreactors for the production of novel compounds, biopolymers, and pharmaceuticals (Van Beilen 2008; Huhns et al. 2008; Bock and Warzecha 2010; Bornke and Broer 2010; Petersen and Bock 2011). As nuclear transformation methods appear to be challenging in accomplishing some of these requirements, targeting the plastid genome becomes the most attractive alternative method. Plastids are plant cell organelles with many essential biosynthetic processes and pathways, such as photosynthesis, photorespiration, as well as metabolism of amino acids, lipids, starch, carotenoids, and other isoprenoids. Depending upon the organ type and environmental conditions, proplastids differentiate into a variety of plastids, such as chloroplasts in photosynthetic tissues, amyloplasts in storage tissue, and chromoplasts in fruits and flowers. Other specialized plastid types include gerontoplasts, the plastids of senescent leaves, which are important for resource allocation, oleoplasts, which are oil storage plastids, and etioplasts, which are found in the final stage of proplastid development in photosynthetic tissues in the dark (Hibberd et al. 1998; van Wijk and Baginsky 2011). Plastids have their own genome and protein-synthesizing machinery; however, nuclear genes encode most of the proteins used in plastids (Pogson and Albrecht 2011).

Plastid genetic engineering is a milestone approach for crop improvement programs, as plastid genomes can be effectively manipulated to attain desirable quality traits. Since plastids are maternally inherited in most of the crop 
species, the introduction of foreign genes into the plastid genome prevents pollen-mediated outcrossing (Bock 2001; Bock and Khan 2004; Maliga 2004) and also offers the possibility of polycistronic operon expression, thus enabling the stacking of multiple-expressed genes in a single transformed event (Staub and Maliga 1995). Furthermore, the polyploidy of the plastome in cells facilitates the high-level transgene expression (Maliga and Bock 2011). The expression of transgenes in transplastomic plants is more stable and uniform, as transgene integration always occurs by homologous recombination and is not affected by position effects or epigenetic gene-silencing mechanisms (Svab et al. 1990; Bock 2001), which occasionally occur in nuclear transformants (Kooter et al. 1999).

Daniell and McFadden (1987) provided the first proof of the uptake and expression of foreign genes in isolated plastids from dark-grown cucumber cotyledons. Soon after, Boynton et al. (1988) used high-velocity tungsten microprojectiles for plastid transformation of the unicellular alga Chlamydomonas reinhardtii. Since then, this concept has been extended to a number of crop species. In the Solanaceae family, chloroplast transformation has been reported in tobacco (Svab et al. 1990; O'Neill et al. 1993; Svab and Maliga 1993; Koop et al. 1996), tomato (Ruf et al. 2001; Nugent et al. 2005; Wurbs et al. 2007), petunia (Zubko et al. 2004), potato (Sidorov et al. 1999; Nguyen et al. 2005; Segretin et al. 2012; Valkov et al. 2011), and eggplant (Singh et al. 2010). Among these, tobacco has been the most important model crop for plastid genetic engineering, and a number of pharmaceutical and agronomically important genes have already been introduced into the tobacco plastid genome. However, its efficiency and applicability are rather limited, and reports of successful transgene expression are still scanty in other Solanaceae species. In this review, we summarize the various aspects of plastid transformation, including integration and expression of foreign genes into the plastid genome of important Solanaceae crops for various agronomical, industrial, and pharmaceutical applications. Furthermore, the current status and future prospects of plastid transformation in Solanaceae crop plants are also discussed in detail.

\section{Requirements for plastid transformation}

Plant regeneration system

For any successful study of genetic transformation, an efficient plant regeneration system is a prerequisite. The ability of Solanaceae plants to respond well in tissue culture, particularly plant regeneration from cultured seedling explants (cotyledons and hypocotyls), cells and protoplasts, has allowed the application of various biotechnology techniques for management of genetic resources and improvement of these crop plants. However, compared with tobacco regeneration systems, other Solanaceae family crops, such as tomato, potato, eggplant, and petunia regeneration systems, are several times lower, and significant differences have been observed in plastid transformation frequencies (Sidorov et al. 1999; Zubko et al. 2004; Gargano et al. 2005; Singh et al. 2010).

Sidorov et al. (1999) described the stable chloroplast transformation of potato by microprojectile bombardment of leaf explants; on average, one transplastomic event was recovered from 15 to 30 bombarded plates. Similarly, a lowtransformation frequency of two per 21 bombarded plates was reported in eggplant with stem explants (Singh et al. 2010). The efficiency of plastid transformation in leaf explants of Petunia hybrida (Zubko et al. 2004) is of one plant per 10 bombarded plates. This was much lower than the frequency of one to five plants per bombardment obtained in Nicotiana tabacum (Svab and Maliga 1993; Iamtham and Day 2000), but it was comparable to plastid transformation efficiencies obtained in leaf explants of tomato (Ruf et al. 2001) and potato (Sidorov et al. 1999; Nguyen et al. 2005). However, with the improved regeneration protocol, transplastomic tomato lines at a higher frequency (on average, one to two transformants per bombardment) were obtained (Wurbs et al. 2007). Valkov et al. (2011) were able to regenerate about one shoot for every bombardment of potato leaf explants, and this efficiency corresponds to a 15-18-fold improvement, compared with previous reports.

\section{Gene transfer methods}

The biolistic (gene gun) technique is the most widely used method, which has proven successful for delivering DNA into plastids in a variety of plant species. The disadvantages of this approach include the possibility of mechanical shearing of large plasmids during particle preparation or delivery, and a chemical reaction with tungsten (a reactive transition metal), which can promote the cleavage or modifications of DNA (Sanford et al. 1993). Furthermore, there is a possibility of occasional unintended co-transformation of chloroplasts and the nucleus (Elghabi et al. 2011a). However, the relatively high efficiency and technical simplicity make biolistic method, the most widespread technology for plastid transformation. The stable introduction of foreign DNA, via the polyethylene glycol (PEG)-mediated uptake of DNA by isolated chloroplasts, has also been conclusively demonstrated in tobacco and tomato (O'Neill et al. 1993; Koop et al. 1996; Eibl et al. 1999; Nugent et al. 2005). This method holds out the promise of the capacity to generate more cells with transformed plastids more readily than by the biolistic procedure. Moreover, the PEG method might be 
useful in species where plant regeneration is possible only from tissues containing plastids that are too small to tolerate the mechanical impact caused by microprojectiles (Koop et al. 1996). However, its feasibility is limited by high technical expertise, low shoot regeneration frequencies, chlorophyll deficiency (variegated leaves), and polyploidy in protoplast-derived plants (Meyer et al. 2009).

Knoblauch et al. (1999) demonstrated the direct microinjection of plasmid DNA into individual chloroplasts of the tobacco mesophyll cells with a galinstan expansion femtosyringe. Green fluorescent protein $(G F P)$ gene driven by a chloroplast ribosomal RNA (rRNA) promoter was transiently expressed in attached leaves of tobacco after $24 \mathrm{~h}$ of injection and was subsequently detected in several chloroplasts in the injected cell. It was concluded that possibly plasmid DNA leakage occurred from the capillary or from the chloroplast on withdrawal of the capillary, which was subsequently taken up by other chloroplasts. Later, van Bel et al. (2001) explained it as a possible interplastidic GFP movement by transient connections known as stromules.

To exploit an alternative approach to the development of plastid transformation technology for other recalcitrant species of Solanaceae, Kuchuk et al. (2006) described the use of remote cytoplasmic hybrids, which was based on two somatic hybridization steps. Initially, they produced remote hybrids (cybrids) carrying the nucleus of tobacco, an easily transformable species, and plastids of the recalcitrant Solanaceae species. Cybrid protoplasts were then subjected to PEG-mediated plastid transformation (Koop et al. 1996). Later, protoplasts (with defective nucleus) from cybrid transplastomic plants were asymmetrically fused with protoplasts of the recalcitrant species, which originally provided the plastids in the first somatic hybridization step. Thus, the successful genetic transformation of plastids of five species of Solanaceae, such as Scopolia carniolica, Physochlaina officinalis, Salpiglossis sinuata, Lycium barbarum, and recombinant $N$. tabacum $/ S$. tuberosum (potacco), was achieved through the use of high regeneration and transformation potential of intermediary "clipboard" hosts (plastiddefective $N$. tabacum). However, this approach has certain limitations, such as the number of steps involved, increased duration of genetic manipulations, genetic variability, and mitochondrial DNA recombination of cybrids. A similar approach was exploited by Sigeno et al. (2009) for intergeneric transfer of transformed chloroplasts from tobacco into petunia by asymmetric somatic hybridization. Tobacco strain whose plastids had been transformed with aadA and $M D A R$ (monodehydroascorbate reductase) genes were used as a source of transformed plastids, and it was suggested that these studies could well expand the potential for the practical use of transplastomic tobacco and for the genetic improvement of other economically important Solanaceae crops. Moreover, cybridization between readily available transplastomic tobacco lines and cultivated Solanaceae crops would be simple with substantially reduced time duration.

\section{Plastid transformation vector and transgene expression}

In general, two distinct components are required to construct the final chloroplast transformation vector system: a vector containing the flanking sequences, left flanking sequence, and right flanking sequence, and the sequences required for efficient transgene expression (expression cassette) (Fig. 1a, b). Flanking sequences are the DNA sequences from the chloroplast genome, which are homologous to the desired site of integration. Their function is to facilitate the sitespecific recombination and define the integration site of the transgene. Therefore, the flanking sequence must be specific to the plastid genome being targeted; these sequences are approximately $1 \mathrm{~kb}$ in size and are located on either side of the expression cassette (Fig. 1a, b). The most commonly used site of integration is the transcriptionally active intergenic region between the trnI-trnA genes within the rRNA operon, which is placed in the inverted repeat (IR) region of the chloroplast genome (Verma and Daniell 2007). The expression cassette (Fig. 1) includes a selectable marker $(S M)$ gene and the gene of interest (GOI), either driven by a single promoter (Pro) (Fig. 1a) or by separate promoters (Fig. 1b), flanked by the $5^{\prime}$ and $3^{\prime}$ untranslated regions (UTRs) of plastid genomes.

Earlier, plastid transformations were carried out with vectors designed for tobacco transformation, as the tobacco homologous flanking sequences present in these transformation vectors share a very high homology to the corresponding sequences of plastid DNA in other Solanaceae crops (Sidorov et al. 1999; Berger et al. 2005; Nguyen et al. 2005). Therefore, the efficient integration of such sequences in these species via homologous recombination was apparent. However, Ruhlman et al. (2010) emphasized the role of endogenous regulatory elements and flanking sequences for efficient chloroplast expression. Transplastomic tobacco or lettuce lines with heterologous $p s b A$ promoters, 5' UTR and 3' UTRs showed reductions of $80 \%$ anthrax protective antigen (PA) and $97 \%$ human proinsulin fused with the cholera toxin, B-subunit (CTB-Pins) expression, when compared with endogenous $p s b A$ regulatory elements. Thus, the use of heterologous gene regulatory elements could substantially reduce the transgene expression, due to transcript instability, differential affinity for RNA-binding proteins and reduced translational efficiency (Ruhlman et al. 2010).

Variations in accumulation of transgene transcripts and their differential translatability are attributed to the plastid constructs with different promoters and UTRs (Eibl et al. 1999; Zhou et al. 2008). For instance, a 3-fold increase in 


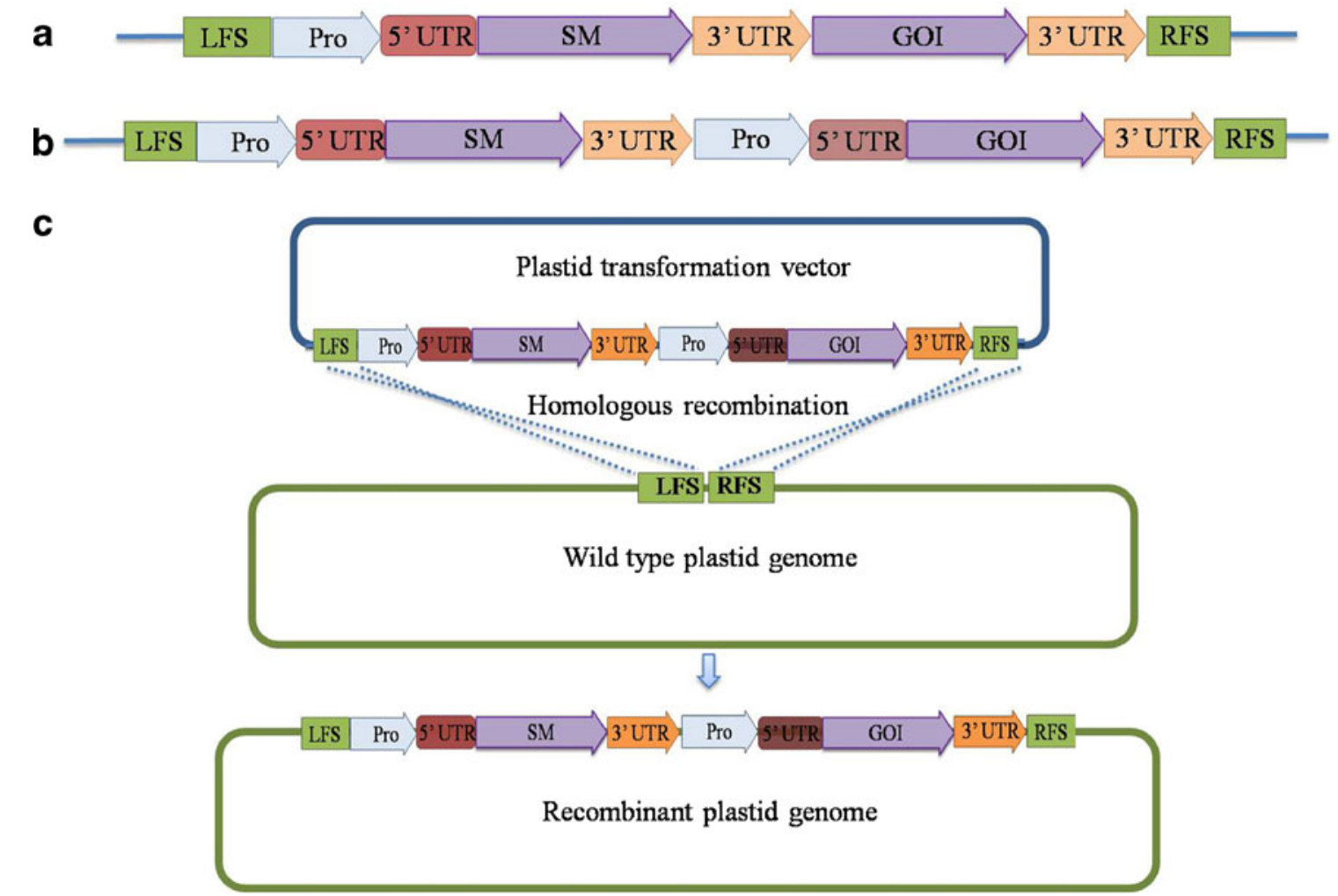

Fig. 1 a Chloroplast expression vector cassette with $S M$ and $G O I$ driven by separate promoters. b Chloroplast expression vector cassette with $S M$ and GOI driven by a single promoter (Pro). c Homologous recombination between plastid transformation vector and wild-type plastid genome

the amount of uidA transcripts was achieved with exchange of the rpl32 3' UTR for the $r b c L$ or $p s b A$ 3' UTRs, but did not significantly influence the amount of $\beta$-glucuronidase (GUS) protein accumulation in transplastomic tobacco plants (Eibl et al. 1999). The atpI promoter and the 3' UTR from the tobacco rps 16 gene facilitated expression of the bacterial lycopene $\beta$-cyclase gene, with 4-fold enhanced pro-vitamin A content of the tomato fruits (Wurbs et al. 2007). Similarly, a drastic increase in the abundance of HIV fusion antigen, $p 24-n e f$, messenger RNA (mRNA) was achieved in tomato fruit through controlling the transcription of transgenes using the full-length tobacco plastid rRNA operon promoter (Zhou et al. 2008).

Recently, Valkov et al. (2011) demonstrated the roles of alternative $5^{\prime}$ UTR and 3' UTRs on transcript stability and translatability of plastid genes in potato. A significant positive effect of $\operatorname{clpP} 5^{\prime}$ regulatory sequences on translatability, particularly in non-green plastids was found (Valkov et al. 2011), which is in agreement with expression profile analyses that indicated $c l p P$ as being one of the less downregulated genes in tubers, compared with leaves (Valkov et al. 2009). In leaves, the accumulation of GFP was about $4 \%$ of the TSP, with constructs containing the plastid rRNA operon promoter $(r r n)$ and a synthetic $r b c L$-derived 5' UTR, whereas, with the $c l p P$ promoter and $c l p P 5^{\prime}$ UTR sequence from the $\operatorname{clp} P$ gene, it was about $0.6 \%$ of the TSP. However, in tubers, GFP expression was equally detectable (up to approximately $0.02 \%$ of the TSP) with plants transformed with both constructs (Valkov et al. 2011). As protein accumulation in plants containing constructs with the rrn promoter is generally accompanied by high expression in leaves, a potential use of the $c l p P 5^{\prime}$ regulatory sequences can be envisaged in cases where recombinant protein accumulation is required in amyloplasts, but not in chloroplasts (Valkov et al. 2011). Apparent differences were also observed between the constructs with distinct $3^{\prime}$ UTRs, but the same $5^{\prime}$ regulatory sequences, suggesting the role of $3^{\prime}$ UTRs on transcript stability and accumulation in amyloplasts (Valkov et al. 2011). Plants with the bacterialderived $r r n B$ terminator accumulated five- and 7-fold more $G F P$ transcripts than plants with $p s b A$ and rpoA $3^{\prime}$ UTRs, respectively, suggesting a positive role of the $\operatorname{rrn} B$ terminator in mRNA stability (Valkov et al. 2011). Segretin et al. (2012) used plastid constructs with flanking sequences and regulatory elements derived from tobacco and achieved a high-level expression of GUS protein (up to $41 \%$ of the TSP) in mature transplastomic potato leaves, which was comparable to expression levels obtained in tobacco. Their results suggest that heterologous flanking sequences and regulatory elements derived from tobacco can also be effectively used for plastid transformation of other Solanaceae species. 


\section{Selection system}

Plastid genetic engineering in higher plants typically involves a stable introduction of the antibiotic-resistance gene as a selection marker, along with the gene of interest. For any successful plastid transformation, an efficient selection marker is required for organelle sorting out during repeated cell divisions in vitro, in order to achieve regeneration of homoplasmic transplastomic shoots (Bock 2001; Maliga 2004). Initially, the relatively low transformation frequency was observed with antibiotic-resistant 16S rRNA allele as a selectable marker. This was most probably due to the recessive mode of action of the rRNA marker during the selection phase as it conferred antibiotic resistance only to those few chloroplast ribosomes that had received their $16 \mathrm{~S}$ rRNA molecule from hardly any initially transformed plastid DNA copies in a cell. Thus, antibiotic-resistant $16 \mathrm{~S}$ rRNA allele was not considered as an efficient selectable marker for plastid transformation (Bock 2001; Nugent et al. 2005). However, vectors with naturally occurring recessive point mutations may be more acceptable than dominant bacterial antibiotic-resistance genes and may obviate the need for marker-excision technologies. Nevertheless, the point mutation conferring antibiotic insensitivity cannot be subsequently removed, it being a part of an essential plastid gene associated with the production of functional ribosomes (Nugent et al. 2005). In contrast, antibiotic-inactivating marker genes provide dominant drug resistance to the recipient chloroplast, and even a single transformed plastid genome copy is sufficient to detoxify the entire organelle (Bock 2001).

Plastid transformation is usually achieved with the use of antibiotic-resistance genes, such as nptII, aphA-6, and aadA genes. The foremost and commonly used chloroplast-specific antibiotic resistance marker is aadA, conferring resistance to a number of antibiotics of the aminoglycoside type, including spectinomycin and streptomycin (Goldschmidt-Clermont 1991). Transformation efficiency with the chimeric aadA gene is about 100 -fold greater than the antibiotic resistance conferred by mutations in 16S rRNA genes (Svab et al. 1990; Svab and Maliga 1991). The most efficient and routinely used selectable markers have been spectinomycin and kanamycin selections; however, the kanamycin selection appears to be less efficient, as it produces a significant background of nuclear transformants (Svab and Maliga 1993). Recently, Li et al. (2011) used chloramphenicol acetyltransferase (CAT) as a selectable marker and obtained homoplastic tobacco chloroplast transformants with no spontaneous antibiotic-resistant mutants. On the basis of their results, they proposed that the CAT gene can be used as a novel selectable marker for plastid transformation in higher plants. On the contrary, use of the herbicide selection system is known to have a detrimental effect on the plant system. The bacterial bialaphos resistance (bar) gene, coding for phosphinothricin acetyltransferase (PAT), has been used as a plastid selection marker. The plastidial expressed bar gene would not be suitable for the direct selection of transplastomic lines due to the inefficient inactivation of phosphinothricin in the cytoplasm by the plastid-localized PAT even with the bar gene expressed at a higher level $(>7 \%$ of the TSP). This indicates that subcellular localization rather than the absolute amount of the enzyme is critical for direct selection of transgenic clones (Lutz et al. 2001).

Green fluorescent protein has been an excellent candidate for non-destructive monitoring of gene expression in subcellular compartments, such as chloroplasts, mitochondria, endoplasmic reticulum, actin cytoskeleton, and nuclei, through the addition of signal peptides (Koehler et al. 1997). GFP was transiently expressed in non-green tissues of a number of crops after biolistic bombardment (Hibberd et al. 1998). It has been reported that high expression of GFP could affect the plant morphology or inhibit plant regeneration (Haseloff and Siemering 1998). However, a high level expression of GFP ( $5 \%$ of the TSP) in chloroplasts of potato had no apparent deleterious effect, perhaps due to the organelle compartmentalization (Sidorov et al. 1999), suggesting that GFP expression would be a valuable marker for screening of non-photosynthetic plastid transformants at the early stages of selection. Furthermore, several photosynthesis-deficient plastid mutants ( $\triangle$ petA, $\triangle y c f 3, \triangle r p o A$, and $\Delta r b c L$ ) have been used for the development of a phenotypic selection system (Klaus et al. 2003; Kode et al. 2006). The reconstitution of the deleted genes in transformants permits the regeneration of photoautotrophictransformed shoots with a visually distinct phenotype comparable to the mutant phenotypes, and overcomes the problems associated with plastid transformation, such as the occurrence of spontaneous mutants or nuclear insertions. In addition to the benefits offered by the visual selection, they also facilitated the rapid recovery of homoplasmic lines. A combination of dominant selectable markers with a visual screening system for the early and conclusive detection of plastid transformants has also been successfully achieved (Klaus et al. 2003).

Excision of marker genes and some alternative strategies

Incorporation of a selectable marker gene along with the gene of interest in the plastid genome is essential to obtain homogeneous plastid genome copies in a plant cell. However, once homoplasmic transplastomic plants are obtained, the marker gene is no longer necessary, and removal of the marker gene enables multiple cycles of transformation with the same selection marker gene. Moreover, integration of antibiotic/herbicide-resistance genes in transformed plants 
raises environmental and health concerns toward the commercialization of transgenic plants. Therefore, efficient methods for complete elimination of marker genes from plastid transformants are necessary to ensure the safety of human health and the environment.

To date, a number of strategies have been employed for the removal of marker genes from the transplastomic plants (reviewed in Lutz and Maliga 2007; Upadhyaya et al. 2010; Day and Goldschmidt-Clermont 2011). One of these approaches is based on the deletion of marker genes by spontaneous homologous recombination via direct repeats flanking the marker gene (Iamtham and Day 2000). However, homology-based marker excision relies on secondary recombination and segregation of plastid DNA in an inherently genetically unstable, heteroplastomic plant, which makes the attainment of marker-free transplastomic plants difficult (Lutz and Maliga 2007). The second approach relies on co-transformation-segregation of selectable and non-selectable marker genes in a genetically unstable, segregating plastid DNA population (Ye et al. 2003). Nevertheless, obtaining stable transplastomic plants through genetically unstable and segregating plastid genome populations is difficult. The third approach is the excision of marker genes with the use of site-specific phage recombination systems, Cre/LoxP or phiC31/attB/attP (Lutz et al. 2007). This system requires additional steps of integration and removal of plastid-targeted phage recombinases from transplastomic plants. Fourth approach is the transient cointegration of the marker gene, which relies on antibiotic/ phenotypic selection of plastid mutants (Klaus et al. 2004). However, this method requires extra effort to isolate and propagate the plastid mutants needed to facilitate the identification of desirable recombination events (Day and Goldschmidt-Clermont 2011). Considering these limitations, the development of a more sophisticated system for generation of marker-free transplastomic plants becomes a necessity, which could facilitate the production of transplastomic plants with a minimum number of manipulations, thereby reducing the possibility of any unwanted recombination effects.

Alternative strategies that have also been reported, without the use of antibiotic/herbicide selection markers, are using those genes that are naturally present in plants and through conferring a metabolic or developmental advantage to the transformants. Several sugar or sugar alcohols and amino acid analogues have been used as positive selection systems for the production of marker-free transgenic plants (Penna et al. 2002; Barone et al. 2009). Attempts were made to use betaine aldehyde dehydrogenase $(B A D H)$ as a selection marker gene (Daniell et al. 2001a; Day and Goldschmidt-Clermont 2011), which accumulates in the plastids of a few plant species adapted to dry and saline environment, which is involved in the conversion of toxic betaine aldehyde (BA) to non-toxic glycine betaine (Rathinasabapathi et al. 1994). However, it was found that selection with BA was non-reproducible, and it can be stated that the BA selection method is not a reliable approach for plastid transformation (Maliga 2004; Whitney and Sharwood 2008). Barone et al. (2009) developed a selection system based on the tryptophan feedback-insensitive anthranilate synthase (AS) $\alpha$-subunit gene of tobacco $(A S A 2)$ as a selective marker, with indole analogue 4-methylindole (4MI) or the tryptophan analogue 7-methyl-DL-tryptophan (7MT) as the selection agents. The use of the ASA2/7MT or 4MI selection system could facilitate the expansion of plastid transformation technology to crops that are naturally resistant to spectinomycin and for which a specific selection system still has to be established (Barone et al. 2009).

Features that have been the target of plastid genetic engineering of Solanaceae crop plants include increased photosynthetic efficiency, biofortification, abiotic stress tolerance, herbicide resistance, pest and disease resistance, and the use of plants as factories for producing biopolymers and biopharmaceuticals. In the following sections, the progress made in these areas will be discussed in detail.

\section{Photosynthetic efficiency}

Chloroplast is an obvious candidate for increasing photosynthetic efficiency, providing one of the attractive avenues to increase the crop yields. One such example is the hybrid $\mathrm{RuBisCO}$, which could lead to an increase in the production of food, fiber, and renewable energy (Spreitzer and Salvucci 2002; Genkov et al. 2010). Over the past few years, extensive work has been carried out to engineer RuBisCO to alter its enzymatic properties (Kanevski et al. 1999; Andrews and Whitney 2003; Raines 2006; Parry et al. 2007) and, in particular, its large chloroplast-encoded catalytic subunit as a target for engineering to increase the net $\mathrm{CO}_{2}$ fixation in photosynthesis. Naturally occurring RuBisCOs with superior catalytic turnover rates and better specificity have been found among the red algae and $\mathrm{C}_{4}$ plant species (Von Caemmerer and Evans 2010). Kanevski et al. (1999) demonstrated the feasibility of using a binary system in which different forms of the large subunit of RuBisCO gene $(r b c L)$ are constructed in a bacterial host and then introduced into a vector for homologous recombination in transformed chloroplasts to produce an active, chimeric enzyme in vivo. Transplastomic tobacco lines expressing the sunflower $r b c L$ gene synthesized a hybrid form of enzyme with large subunits of sunflower and small subunits $(r b c S)$ of tobacco with enzymatic properties similar to the hybrid enzyme (Kanevski et al. 1999). However, transplastomic line expressing the cyanobacterial $r b c L$ gene failed to assemble correctly using the tobacco chloroplast protein folding 
machinery, and it neither produced the large subunit nor showed any enzyme activity. Similarly, Zhang et al. (2011) produced transplastomic tobacco plants with the $r b c L$ gene replaced by tomato-derived $r b c L$ and demonstrated that the tomato large subunit was assembled with the tobacco small subunit into functional RuBisCO.

Although the large subunit of $\mathrm{RuBisCO}$ contains the catalytic active site, small subunit can also influence the carboxylation catalytic efficiency and $\mathrm{CO}_{2} / \mathrm{O}_{2}$ specificity of the enzyme, as well as contribute significantly to the overall catalytic performance of RuBisCO (Genkov et al. 2010; Whitney et al. 2011). However, engineering the native or foreign $r b c S$ genes in higher plants remains an inexplicable challenge due to the multiple $r b c S$ copies that are located in the nucleus, which essentially precludes $r b c S$ from targeted mutagenic or replacement strategies (Whitney and Sharwood 2008). All these hybrid or foreign RuBisCO enzymes, even when enzymatically competent, displayed impaired biogenesis in planta, mainly due to the problems with subunit folding and assembly. Consequently, many of the resultant plants suffered severe defects in photosynthesis and growth. Thus, manipulation of endogenous RuBisCO has been largely unsuccessful in terms of improving enzyme activity (Zhang et al. 2011). Although the recent developments in improving the performance of RuBisCO seems to be reluctant, this research has provided novel insights into structural and functional relationships and has considerably enhanced our understanding of this key enzyme, providing new opportunities to develop more productive crop plants (Whitney and Andrews 2001; Zhang et al. 2002; Dhingra et al. 2004). Additionally, the engineering of metabolic and photosynthetic activities for increasing sink strength, especially in non-leaf sinks, such as fruits and tubers, will have a tremendous potential to improve the crop yield.

\section{Abiotic stress tolerance}

Conventional plant breeding methods to accelerate the abiotic stress tolerance of Solanaceae crop plants have met with limited success, plus efforts to improve the abiotic stress tolerance are complicated by genetic complexity (Waterer et al. 2010). Therefore, genetic engineering would provide a potentially useful tool for improving abiotic stress tolerance of the Solanaceae crops with newly developed crop varieties to adhere to high yield and quality expectations.

Sigeno et al. (2009) developed the transplastomic petunia containing genetically transformed tobacco chloroplast, expressing monodehydroascorbate reductase (MDAR), one of the antioxidative enzymes involved in the detoxification of the ROS under various abiotic stresses. The MDAR gene was transcribed in the somatic cybrids of petunia as the transplastomic tobacco plants. Similarly, transplastomic tobacco plants expressing either a tobacco mitochondrial superoxide dismutase $(M n S O D)$ or an E. coli glutathione reductase (gor) gene, which is associated with the scavenging of ROS showed improved tolerance for various abiotic stresses. Thus, the level of enzymes associated with ROS scavenging can be effectively modified through direct chloroplast transformation (Poage et al. 2011).

The possibility of altering the unsaturation levels of fatty acids in plant lipids by plastid genetic engineering could provide the plants with abiotic stress tolerance as well as improved nutritional value. Craig et al. (2008) produced transplastomic tobacco plants, which express a Delta-9 desaturase gene from either the wild potato species Solanum commersonii, or the cyanobacterium, Anacystis nidulans, which controls the insertion of double bonds in fatty acid chains, and demonstrated the increased cold tolerance in transplastomic plants with altered leaf fatty acid profiles. Earlier integration and expression of a Delta-9 desaturase gene has also been demonstrated in potato plastids in order to achieve higher content of unsaturated fatty acids, a desirable trait for stress tolerance of higher plants, in addition to improved nutritional value (Gargano et al. 2003, 2005).

To cope with adverse environmental conditions, many plants express low molecular weight compounds collectively called osmoprotectants, which are typically sugars, alcohols, proline, and quaternary ammonium compounds (Glick and Pasternak 1998). Transplastomic tobacco plants, which express the yeast trehalose phosphate synthase (TPS1) gene, showed an accumulation of trehalose several times higher than the best surviving nuclear transgenic plants without any pleiotropic effects (Schiraldi et al. 2002; Lee et al. 2003). Another highly effective osmolyte glycine betaine (GB) is known to accumulate only in few plant species during drought or high salinity and protects the plant by maintaining an osmotic balance within the cell (Robinson and Jones 1986; Rathinasabapathi et al. 1994). Transplastomic tobacco plants, which were transformed with a gene encoding choline monooxygenase (BvCMO) from Beta vulgaris, were able to accumulate GB in leaves, roots, and seeds and showed improved tolerance to toxic levels of choline, in addition to exhibiting tolerance to salt/drought stress, when compared with wild-type plants. Transplastomic plants also demonstrated higher net photosynthetic rates and an increased quantum yield of photosynthesis, even in the presence of salt stress (Zhang et al. 2008).

\section{Herbicide resistance}

Plastid genetic engineering provides increased containment of herbicide resistance genes as plastid genes are not transmitted by pollen. The most commonly used herbicide, 
glyphosate, is a broad-spectrum systemic herbicide known to inhibit the plant aromatic amino acid biosynthetic pathway by competitively inhibiting the 5-enolpyruvylshikimate-3-phosphate synthase (EPSPS), a nuclear-encoded chloroplasttargeted enzyme involved in the biosynthesis of aromatic amino acids (Bock 2007). Most of the transgenic plants resistant to glyphosate are typically engineered to overexpress the EPSPS gene (Ye et al. 2001). As the target of glyphosate resides within the chloroplast, chloroplast transgenic engineering is an ideal strategy for developing glyphosate resistance in plants. Transgenic tobacco plastids expressing the EPSPS gene resulted in the accumulation of over 250 -fold, EPSPS enzymes, when compared with nuclear transgenics (Ye et al. 2001). However, such increased levels of glyphosate-resistant EPSPS did not correlate to increased tolerance to glyphosate. One reason for this discrepancy between protein level and tolerance was that the nuclearencoded gene is expressed at a high enough level to confer resistance in the appropriate cell types, whereas the plastid transgene is not (Ye et al. 2001). Transplastomic tobacco plants expressing the bacterial bar gene linked with spectinomycin resistance ( $a a d A)$ gene for selection of transformants showed a significantly elevated expression level of phosphinothricin acetyltransferase and exhibited field-level tolerance to Liberty, an herbicide containing PPT (Lutz et al. 2001).

On the contrary, tobacco plastome engineering of the hppd (4-hydroxyphenylpyruvate dioxygenase) gene from Pseudomonas fluorescens, which is part of the biosynthetic pathway leading to plastoquinone and vitamin E biosynthesis (Dufourmantel et al. 2007), resulted in the accumulation of HPPD to approximately $5 \%$ of the TSP in transgenic chloroplasts with strong tolerance to the triketone herbicide, Isoxaflutole. Transplastomic tobacco seedlings overexpressing the barley hppd gene showed a higher resistance to another triketone herbicide, Sulcotrione (Falk et al. 2005). Similarly, Wurbs et al. (2007) produced the transplastomic tomato expressing bacterial lycopene $\beta$-cyclase gene, resulting in increased levels of herbicide tolerance to 2-(4-chlorophenylthio)-triethylamine (CPTA), which specifically inhibits lycopene $\beta$-cyclase activity.

\section{Pest and disease resistance}

The Solanaceae family includes some of the most widely cultivated vegetable crops, which are susceptible to several pests and diseases (Afroz et al. 2011; Girhepuje and Shinde 2011). Pest and disease-resistant transgenic plants would provide an effective built-in pest and disease control, in addition to protecting the environment from adverse effects of agrochemicals. Despite significant progress in nuclear transformation, plastid engineering might be particularly useful in those cases where successful resistance engineering crucially depends on high expression levels of the resistance gene and increased gene containment and biosafety.

Most of the approaches make use of insecticidal protoxins produced by a variety of Bacillus thuringiensis strains for pest control. Expression of Cry genes in the plastid genome does not require adjustment of codon usage or any other sequence manipulations (McBride et al. 1995; De Cosa et al. 2001; Chakrabarti et al. 2006). Moreover, multiple gene stacking by polycistronic expression of transplastomic chloroplasts would avoid the retransformation and additional selectable marker gene integration in the plant genome by conventional nuclear gene pyramiding via Agrobacterium-mediated gene transfer (Meiyalaghan et al. 2010). In addition, the absence of insecticidal proteins in transgenic pollen eliminates toxicity to pollen-feeding nontarget insects, thereby increasing the efficacy and safety of transgenic plants throughout the growing season (De Cosa et al. 2001). De Cosa et al. (2001) reported the high expression of insecticidal Bt-toxins in tobacco chloroplasts with no obvious phenotypic defects and shown to process a bacterial operon properly, which expressed the insecticidal Cry2Aa2 proteins at levels up to $46 \%$ of the TSP (solubilized in $\mathrm{NaOH}$, as crystalline Cry inclusion bodies are soluble at high alkaline $\mathrm{pH}$ ). In contrast, significantly delayed plant development of transplastomic tobacco plants expressing Cry9Aa2 gene was associated with an increased accumulation of the TSP $(\sim 10 \%$ in cellular fraction and $\sim 20 \%$ in membrane fraction) (Chakrabarti et al. 2006). Therefore, the possibility of phenotypic defects in the transplastomic plants expressing these insecticidal proteins cannot be ruled out.

DeGray et al. (2001) first reported the disease-resistant transplastomic tobacco plants conferring resistance against a broad range of pathogens expressing MSI-99, an antimicrobial peptide (AMP), and an analog of maganin-2, a defense peptide secreted from the skin of the African clawed frog (Xenopus laevis). AMPs are helical antimicrobial peptide that confers protection against many prokaryotic organisms, due to its high specificity for negatively charged phospholipids, which are typically found in outer membranes of bacteria and fungi (Houston et al. 1997; Biggin and Sansom 1999). In vitro assays with leaf/protein extracts from transplastomic plants showed a highly significant inhibition of growth of bacterial pathogen Pseudomonas syringae pv. tabaci and pre-germinated spores of three fungal species, Aspergillus flavus, Fusarium moniliforme, and Verticillium dahliae. In planta assays with the bacterial pathogen, $P$. syringae pv. tabaci, and the fungal pathogen, Colletotrichum destructivum, showed areas of necrosis around the point of inoculation in control leaves, whereas transplastomic plant leaves showed no signs of necrosis, demonstrating a highdose release of the peptide at the site of infection by chloroplast lysis (DeGray et al. 2001). 


\section{Biofortification}

One of the advantages of genetic engineering is the costeffective production of nutritional compounds, which have the potential to improve the human nutrition and health status. The ability to express multiple genes as an operon makes chloroplast genetic engineering an attractive method for engineering the nutritionally important metabolic pathways. Carotenoids are essential pigments of the photosynthetic machinery in plants and an indispensable component of the human diet. In addition to being potent antioxidants, they also provide the vitamin A precursor, $\beta$-carotene (Apel and Bock 2009). The carotenoid biosynthetic pathway, localized in the plastid, has been thoroughly investigated and several strategies have been used to metabolically engineer the carotenoid biosynthesis in crop plants (Wurbs et al. 2007; Lopez et al. 2008; reviewed in $\mathrm{Lu}$ and Li 2008). Plastid engineering of Solanaceae crop plants for enhanced $\beta$-carotene synthesis would also be possible by overexpression of a single or combination of two or three bacterial genes, $C r t B, C r t I$, and $C r t Y$, encoding phytoene synthase, phytoene desaturase, and lycopene $\beta$-cyclase, respectively.

Wurbs et al. (2007) demonstrated the feasibility of engineering nutritionally important biochemical pathways in non-green plastids by transformation of the chloroplast genome of tomato. The transplastomic tomato expressing bacterial lycopene $\beta$-cyclase gene resulted in the conversion of lycopene to $\beta$-carotene with 4 -fold enhanced $\beta$-carotene content of the fruits. Similarly, Apel and Bock (2009) produced the transplastomic tomato fruits expressing the lycopene $\beta$-cyclase genes from the eubacterium, Erwinia herbicola, and the higher plant daffodil (Narcissus pseudonarcissus). Although expression of the bacterial lycopene $\beta$ cyclase did not strongly alter carotenoid composition, expression of the daffodil lycopene $\beta$-cyclase efficiently converted lycopene into provitamin-A ( $\beta$-carotene), plus accumulated $\beta$-carotene with provitamin-A levels reaching $1 \mathrm{mg} / \mathrm{g}$ dry weight.

All the vitamin E synthesis enzymes are nuclear encoded and imported into the plastid, except for HPPD, which is active in the cytoplasm, catalyzing an early step (conversion of 4-hydroxyphenylpyruvate to homogentisate) in the biosynthetic pathway of tocopherols (Garcia et al. 1999). The hppd gene from Hordeum vulgare, which was expressed in tobacco plastids, accumulated more than twice as much $\alpha$ tocopherol in transplastomic tobacco leaves than wild-type tobacco leaves (Falk et al. 2005). However, overexpression of the hppd gene in plastids did not prove to be advantageous. It has been suggested that homogentisate synthesized in the plastids is not directly accessible to the binding site of the homogentisate phytyltransferase/homogentisate solanesyltransferase, the next enzymes of the tocopherol and plastoquinone biosynthetic pathway (Falk et al. 2005). It was proposed that at least five genes in the vitamin E pathway have to be upregulated in order to enhance its accumulation significantly in oil seed crops (Kinney 2006). Likewise, transformation of the plant chloroplast with any or all these genes, via a multigene construct and a single promoter, would allow their expression to be several times higher (Bock 2007; Day and Goldschmidt-Clermont 2011).

Plastid engineering holds great promise for manipulation of fatty acid biosynthesis pathway genes and contributes to improved food quality and biofuel production. Several biosynthetic reactions of fatty acid biosynthesis are localized in the plastids, which can be effectively targeted via plastid engineering to increase fatty acid production in plants. A number of studies have demonstrated significant progress towards the goal of improving plant fatty acids (reviewed in Rogalski and Carrer 2011). Plastidic acetyl-CoA carboxylase (ACCase) is a key enzyme regulating the rate of de novo fatty acid biosynthesis in plants, composed of three nuclearencoded subunits and one plastid-encoded accD subunit. Madoka et al. (2002) replaced the promoter of the $a c c D$ operon in the tobacco plastid genome with a plastid rRNAoperon promoter $(r r n)$, which directs enhanced expression in photosynthetic and non-photosynthetic organs, and successfully elevated the total ACCase levels in plastids. The transformants displayed extended leaf longevity, a 2-fold increase in seed yield, and just about doubled the fatty acid production. Transplastomic tobacco plants expressing the exogenous Delta-9 desaturase genes showed altered fatty acid profiles and an increase in their unsaturation level in both leaves and seeds (Craig et al. 2008). Plastid genetic engineering can also be efficiently used for synthesis of unusual fatty acids, such as very-long-chain polyunsaturated fatty acids (VLCPUFAs), which are generally absent from plant foods. As plastid engineering offers the advantage of engineering multiple genes in operons, it could allow the expression of four genes (three subunits ORF A, B, C of the polyketide synthase system, and the enzyme phosphopantetheinyl transferase), required for the production of VLCPUFAs (Rogalski and Carrer 2011).

\section{Biopolymer production}

The production of biodegradable polymers as a substitute for petrochemical compounds through transgenic technology is a great challenge for plant biotechnologists (Neumann et al. 2005; Huhns et al. 2009). Polyhydroxybutyrate (PHB), which serves as a carbon storage molecule in the bacteria, has drawn considerable attention from industries due to its potential application in biodegradable plastics and elastic polymers. Polyhydroxybutyrate is synthesized from acetylcoenzyme A, through the consecutive activity of three enzymes of bacterial origin: $\beta$-ketothiolase, acetoacetyl- 
CoA reductase, and PHB synthase. A number of genes encoding synthesis of biodegradable polyester have already been expressed in tobacco plastids with PHB expressions of approximately $0.006-0.1 \%$ of dry weight of leaf samples (Lossl et al. 2003; Arai et al. 2004). Recently, BohmertTatarev et al. (2011) reported the PHB expression up to $18.8 \%$ dry weight of leaf tissue, with use of an optimized gene construct based on their similarity to the codon usage and GC content of the tobacco plastome. The plant-derived collagen and spider silk-elastin fusion proteins have immense uses in biomedical science (Scheller and Conrad 2005). Guda et al. (2000) successfully produced the bioelastic protein-based polymers by integration and expression of the biopolymer gene (EG121), in the tobacco plastid. However, its feasibility of production in quantities and at purities adequate for commercial spinning remains challenging. Recently, Xia et al. (2010) expressed spider dragline silk favorably in metabolically engineered $E$. coli, by overcoming the difficulties caused by its glycine-rich characteristics, thus providing new insight into optimal expression and synthesis of plastid-targeted silk proteins, possibly with increased yields and metabolic compartmentalization with minimal adverse effect on plant systems.

\section{Production of pharmaceuticals}

Plastid transformation technology is set to become a major role player in the production of human therapeutic proteins. An increasing number of pharmaceutical proteins and vaccines have already been produced in the chloroplast of tobacco (Nugent and Joyce 2005; Daniell et al. 2009; Bock and Warzecha 2010; Gorantala et al. 2011; Lössl and Waheed 2011; Maliga and Bock 2011). In a number of cases, extraordinarily high level expression of foreign proteins was achieved in transplastomic tobacco. Abundant local expression of the human serum albumin (HSA) has been achieved in tobacco plastids as inclusion bodies, yielding a recovery of about $0.25 \mathrm{mg} \mathrm{HSA} / \mathrm{g}$ fresh weight, which was well within the range of industrial-scale feasibility (Fernandez-San Millan et al. 2003). Oey et al. (2009) reported the maximum accumulation of a phage lytic protein, PlyGBS ( $>70 \%$ of the TSP) and proved to be extremely stable in transgenic chloroplasts of tobacco. Genes encoding the human somatotropin (hST) (Staub et al. 2000), cholera toxin B subunit (CTB) (Daniell et al. 2001b), tetanus toxin $C$ fragment (TetC) (Tregoning et al. 2003), anthrax protective antigen (PA) (Watson et al. 2004; Koya et al. 2005), HPV16 (human papillomavirus type 16), L1 antigen (Fernandez-San Millan et al. 2003; Lenzi et al. 2008), and antimicrobial peptides retrocyclin-101 (RC101) and protegrin-1 (PG1) (Lee et al. 2011) have been produced in transplastomic tobacco plants.
Production of two or more vaccine fusion proteins could possibly facilitate the easy purification and processing and reduction in the cost of production. Expression of foreign proteins in tobacco as fusion associates facilitated a significant accumulation of hST and interferon-gamma (IFN-g) (Daniell 2006); non-toxic CTB, genetically fused to 2L21(a linear antigenic peptide from the VP2 capsid protein of the canine parvovirus) (Molina and Veramendi 2009), and with human proinsulin (Ruhlman et al. 2007; Boyhan and Daniell 2011). Similarly, production of a multiepitope DPT vaccine fusion protein, containing immunoprotective exotoxin epitopes of Corynebacterium diphtheriae, Bordetella pertussis, and Clostridium tetani, has also been achieved in tobacco chloroplasts (Soria-Guerra et al. 2009). Gargano et al. (2005) reported the transplastomic potato plants with expression of the HPV16 L1 capsid protein fused to a His6 tag. An additional vaccine candidate, the E7 HPV type 16 oncoprotein fused with potato virus $\mathrm{X}$ coat protein $(\mathrm{CP})$, was also expressed in tobacco chloroplasts (Morgenfeld et al. 2009). Recently, Waheed et al. (2011) developed a costeffective alternative approach for VLP-based HPV vaccines. A modified $H P V-16 L 1$ gene, which retained the ability to assemble L1 protein to capsomeres was expressed in tobacco chloroplasts. Capsomeres are considered relatively thermostable and are able to induce the immunogenicity to a level as that of VLPs (virus-like particles) (Schädlich et al. 2009; Lössl and Waheed 2011).

The chloroplast transformation system has also been explored for the production of HIV antigens (McCabe et al. 2008; Zhou et al. 2008). Transplastomic tobacco plants were able to accumulate human immunodeficiency virus type 1 (HIV-1) p24 (the major target of T-cell-mediated immune responses in HIV-positive individuals) protein up to about $2.5-4.5 \%$ of the TSP with correct size and without any post-translational modifications, such as glycosylation or phosphorylation (McCabe et al. 2008). Zhou et al. (2008) successfully expressed the various HIV antigens (p24, Nef, p24-Nef, and Nef-p24) in tobacco and tomato plastids. Optimized p24-Nef fusion gene cassettes increased the p24-Nef antigen protein accumulation to approximately $40 \%$ of the plant's total protein. These results demonstrate the considerable potential of transgenic plastids to produce AIDS vaccine components at a low-cost and high yield.

Genetically engineered starch particles, designated as amylosomes (Dauvillee et al. 2010), were used to produce recombinant anti-malaria vaccines in the unicellular green algae, $C$. reinhardtii. Apical major antigen (AMA1) or major surface protein (MSP1), which is fused to the algal granule-bound starch synthase (GBSS), are efficiently expressed and bound to the polysaccharide matrix. The salient feature of this approach is that the starch is easy to purify and represents a protective environment for bound proteins, as GBSS is known to be remarkably stable with no 
detectable loss of activity, even after years of storage. This system should also be expedient to the production of any recombinant antigens, including vaccine candidates of viruses, bacteria, and other protozoan parasites, plus they could be deployed to starch-producing crop plants, including cereals and potatoes (Dauvillee et al. 2010). These results clearly indicate that plastid transformation is an effective plant-based production platform for nextgeneration vaccines.

\section{Limitations}

The future of chloroplast genetic engineering for a wide range of applications gives us a reason to be optimistic. However, there are several areas of concern that will require attention if the full potential of this technology is to be realized. Low plastid transformation efficiencies of some of the species and inefficient gene expression in non-green plastids, such as potato tuber amyloplasts and chromoplast of tomato and pepper (Brosch et al. 2007; Kahlau and Bock 2008; Valkov et al. 2009), are major constraints for further extension of this technique in Solanaceae. Moreover, gene expression in non-green tissue plastids is largely uncharacterized, compared with leaf chloroplasts and the lack of appropriate tissue-specific regulatory sequences, which function in non-green plastids to achieve efficient transgene expression, is another major obstacle.

Although transgenes are generally efficiently targeted to their desired insertion site, unintended secondary homologous recombination events have been observed during plastid transformation that may hinder an efficient recovery of plastid transformants containing the desired transgene (Svab and Maliga 1993; Iamtham and Day 2000; Gray et al. 2009). It was suggested that these unwanted recombination events could be of common occurrence in chloroplast transformation experiments, as UTRs for plastid transgenes are usually derived from endogenous chloroplast genes (Rogalski et al. 2006). Ahlert et al. (2003) reported that unwanted recombination events were avoided between the $p s b A$-derived $3^{\prime}$ end of the chimeric aadA gene and the endogenous $p s b A$ locus using a short version of the $p s b A 3^{\prime}$ end. Similarly, the length of the $5^{\prime}$ UTR was also reduced to minimize the probability of an unwanted homologous recombination in plastid transformants (Maliga and Bock 2011). Thus, the use of truncated UTRs, and keeping a low number of UTRs is a highly desirable and efficient approach for vector construction. Nevertheless, it is important for the interpretation of RFLP analyses, which are commonly conducted to demonstrate transgene integration and homoplasmy of transplastomic plants (Rogalski et al. 2006).

Most plastid genes are part of operons, expressed as polycistronic mRNAs, and these mRNA transcripts are post-transcriptionally processed into mono- or oligocistronic units, presumably by specific endonucleolytic cleavage (Herrin and Nickelsen 2004; Zhou et al. 2007). Although several previous studies have suggested that the expression of transgenes from polycistronic mRNAs is possible (Staub and Maliga 1995; Quesada-Vargas et al. 2005), poor translation of polycistronic mRNAs has been presumed to be responsible for the cases where transgene expression was drastically low (Nakashita et al. 2001) or unsuccessful altogether (Magee et al. 2004). In most of the cases, this approach has failed due to fundamental differences in operon expression between bacteria and plastids. To overcome this problem, Zhou et al. (2007) described the use of small intercistronic expression elements (IEE), capable of generating stable translatable monocistronic mRNAs through intercistronic cleavage. Separation of transgenes by IEE promotes transgene stacking in operons, thus expanding the range of applications of transplastomic technology (Zhou et al. 2007). Applications of the IEE can be extended to the introduction of multiple disease resistance, the coexpression of selectable marker and reporter genes, as well as the engineering of complex biochemical pathways (Ye et al. 2001), and the production of biopharmaceuticals in plastids (Bock 2007).

Highly variable expression of foreign proteins in tobacco chloroplasts has been reported, ranging from 0.002 to $72 \%$ of the TSP (Lee et al. 2006; Oey et al. 2009; Sim et al. 2009; Ruhlman et al. 2010). Nevertheless, massive expression of foreign proteins resulted in phenotypic alterations and delayed plant development in transplastomic plants (Chakrabarti et al. 2006; Oey et al. 2009) due to severe exhaustion of the endogenous gene expression of the chloroplast evident from the strongly downregulated $\mathrm{RuBisCO}$, which constitutes the major leaf amino acid store (Oey et al. 2009; Bally et al. 2009). The constitutive expression of biopolymers and metabolic pathway enzymes in plastids also resulted in mutant phenotypes, adversely affecting the growth and development of transplastomic plants because of either metabolite toxicities, interference with photosynthesis, or disturbance of the plastid endomembrane system (Lossl et al. 2003; Neumann et al. 2005; Hennig et al. 2007; Huhns et al. 2009).

Protein stability has recently emerged as a major bottleneck to foreign protein accumulation in transgenic plastids (Apel et al. 2010; Elghabi et al. 2011b). Although several recombinant proteins were expressed to levels more than $10 \%$ of the TSP (reviewed in Daniell et al. 2009; Bock and Warzecha 2010), there are several cases where a very low accumulation of foreign proteins was reported (BirchMachin et al. 2004; Bellucci et al. 2005; Lee et al. 2006). It appears that accumulation of foreign proteins in transgenic chloroplasts is often limited by protein stability (BirchMachin et al. 2004; Zhou et al. 2008; Oey et al. 2009), 
although lack of RNA stability can also be responsible for unsuccessful expression of plastid transgenes (Wurbs et al. 2007; Elghabi et al. 2011b). Apel et al. (2010) demonstrated that major protein stability determinants are located in the $\mathrm{N}$ terminus, and the penultimate $\mathrm{N}$-terminal amino acid residue has an important role in determining the protein halflife. Recently, Elghabi et al. (2011b) also investigated the possibility of enhancing the expression of an unstable recombinant protein, the HIV-1 fusion inhibitor cyanovirin-N $(\mathrm{CV}-\mathrm{N})$ in transgenic plastids by protecting its $\mathrm{N}$ and/or Cterminus with polypeptide sequences taken from the highly stable proteins, GFP and PlyGBS. It is possibly by impeding the endoribonucleolytic cleavage of the $\mathrm{CV}-\mathrm{N}$ coding region and thus exerts the observed stabilizing effect on the mRNA (Elghabi et al. 2011b). In similar experiments, an efficient fusion of a downstream box, composed of the 10-15 codons immediately downstream of the start codon, allowed highlevel accumulation of active bacterial $\beta$-glucosidase in tobacco chloroplasts (Gray et al. 2011). Significant increase in transcript stability can be achieved by inserting sequences from stable mRNAs between the 5' UTR and the coding region of the transgene of interest and highlights a possible solution in all those cases, where transgene expression is limited by mRNA accumulation (Elghabi et al. 2011b).

In order to confirm the homoplasmy of all transplastomic lines, it is necessary to perform seed assays, which are the most sensitive tests available to assess homoplasmy. A lack of segregation of antibiotic resistance in the $\mathrm{T} 1$ generation demonstrates the homoplasmy and confirms the uniparental maternal transgene inheritance (Hagemann 2002; Maliga 2004). However, obtaining homoplasmic transplastomics is quite challenging, and several additional rounds of selection adversely affect the regeneration efficiency of recalcitrant species. Even after several rounds of antibiotic selection, complete intraorganellar homoplasmy is difficult to achieve in species with poor regeneration capacity (Bock 2001) and upon transfer to the selection-free media, segregation of plastids with wild-type plastid genomes reoccurs, thereby resulting in the heteroplasmy of transplastomics (Wei et al. 2011).

Transgene containment is another key concern in genetically modified crops, especially for those species with outcrossing wild relatives. Consequently, engineering foreign genes in the chloroplast genome would provide enhanced transgene containment by virtue of uniparental maternal inheritance of plastids. However, there are two mechanisms by which plastid transgenes can escape through pollen at a low frequency: occasional paternal/biparental transmission of plastids (Ruf et al. 2007; Svab and Maliga 2007; Matsushima et al. 2008) and transfer of transplastome genes to the nuclear genome (Huang et al. 2003; Stegemann et al. 2003; Sheppard et al. 2011). Transgene containment, via maternal inheritance, would not be applicable to a few crops, such as alfalfa and evening-primrose, in which maternal inheritance is not a rule. They exhibit an equal distribution of plastids during the first pollen mitosis into the generative and vegetative cells; therefore, sperm cells transmitting plastids into egg cells during fertilization, is called biparental plastid transmission (Daniell 2007; Matsushima et al. 2008). In tobacco, a very low frequency of occasional paternal transmission of transgenic plastids was observed under experimental conditions in the range of $1 \times 10^{-4}$ to $2.86 \times 10^{-6}$ (Ruf et al. 2007; Svab and Maliga 2007). The frequency of occasional paternal transmission of transgenic plastids under field conditions, where transgenic and nontransgenic plants were grown separately, suggested being in the range of $10^{-8}$ (Ruf et al. 2007), thereby demonstrating that plastid transgene transmission is less likely to occur under field conditions. Although organellar DNA transfers very frequently into the nucleus, most of it is quickly deleted, decayed, or is alternatively scrapped, and a very small proportion of it gives rise, immediately or eventually, to functional genes (Lloyd and Timmis 2011). Nuclear transfer of the plastid gene would normally not result in transgene expression, due to the absence of a nuclear promoter, yet accidental integration and subsequent rearrangements could bring a transgene into context with an existing nuclear promoter (Stegemann and Bock 2006; Lloyd and Timmis 2011).

Although the level of containment conferred by the transplastomic plants is suggested to be convincingly sufficient (Ruf et al. 2007; Svab and Maliga 2007), there are numerous applications where the absolute containment for such transplastomic lines is required, for instance, in the case of production of industrially important therapeutic proteins and vaccines. To achieve this, plastid transformation should be accompanied with one or more viable containment strategies, such as reversible cytoplasmic male sterility (Ruiz and Daniell 2005), genetic use restriction technology, and transgene mitigation strategies (Ruf et al. 2007; Day and Goldschmidt-Clermont 2011). Another approach, which might help to minimize functional transgene escape through pollen, is the incorporation of RNA editing sites in the plastid transgene. Sheppard et al. (2011) reported that the RNA editing of chloroplast transgenes may reduce the functional gene transfer to nucleus but may not eliminate the plastid-to-nucleus gene transfer. An even more efficient approach that has been employed in the past to avoid functional gene transfer to the nucleus is the use of chloroplast group II introns. Chloroplast group II introns are known to interrupt reading frames in fungal and plant mitochondria, in plastids, and in bacteria. Bock and Maliga (1995) investigated the splicing of $a t p F$, a plastid group II intron. They observed that after the insertion of atpF intron into a chimeric plastid uidA gene, the GUS reporter gene expression became dependent on the correct splicing of intron. 
Recently, in a similar report, Petersen et al. (2011) investigated the putative role of two group II introns that interrupt a plastid gene (ycf3), whose removal is essential for synthesis of a functional ycf3 polypeptide and thus for photosynthetic activity. Based on their results, they suggested that the splicing of one intron can depend on the presence of another intron, and the group II introns can have a selective value in that their loss can cause a decline in fitness (Petersen et al. 2011). To date, no single strategy has been established that is broadly applicable, but a combination of approaches would be most efficient for engineering eco-friendly transgenic crops.

A major concern with plastid genetic engineering of higher plants might be the use of antibiotic-resistance genes as the selectable markers. The large number of chloroplast genome copies in a plant cell as well as the prokaryotic features of their gene expression machinery might enhance the probability of horizontal gene transfer from plants to bacteria living in the soil or a gastrointestinal tract. However, to date, such risks have been found to be negligible. Moreover, the spread of antibiotic-resistance genes from crops among bacteria does not signify any selective advantage because various resistance genes and other genetic determinants are already naturally present in the environment (Demanèche et al. 2008; Talianova and Janousek 2011). Nevertheless, the removal of antibiotic marker genes and, following alternative strategies, possibly avoids such risks associated with transplastomic plants. The continuous monitoring and evaluation of potential risks associated with transgenic plants would further ensure the biosafety and ease the public concerns of GM crops.

Finally, the financial and political obstacles that hinder the introduction of new vaccines in developing countries are major challenges of these research programs. Design of translational research programs is still in its infancy, and it is important to design them in a way that is responsive to the needs of national policy makers of any particular country.

\section{Future perspectives}

Several improvements in plastid transformation vectors, transformation procedures, selection systems, and regeneration protocols have recently made it possible to produce industrially important proteins, plus plants with important agronomic traits to a somewhat greater extent. Plastid genetic engineering can be effectively used to modulate entire metabolic pathways or even to induce the expression of pathways in organs where they do not normally occur. The development of non-green plastid expression vectors remains an important goal for the realization of many of the potential benefits of plastid genetic engineering. Generally, potato amyloplasts exhibit a low transcription rate and increased transcript stability of plastid genes (Brosch et al. 2007; Valkov et al. 2009) and foreign protein accumulation was found to be several-fold lower in non-photosynthetic microtubers than in green leaves (Sidorov et al. 1999). Although transplastomic tomato leaf chloroplasts accumulated high level of foreign proteins ( $>40 \%$ of the TSP), fruit chromoplasts were able to express the transgene to about $50 \%$ of the expression levels achieved in leaf chloroplasts (Ruf et al. 2001). Expression levels achieved in potato amyloplasts and tomato chromoplasts (Sidorov et al. 1999; Zhou et al. 2008; Valkov et al. 2011) may be adequate to manipulate the expression of enzymatic proteins for metabolic engineering purposes but are still too low to exploit as a production platform for proteins of pharmaceutical or industrial interest. Recently, a systematic characterization of gene expression in tuber amyloplasts and chromoplasts of tomato and pepper revealed that gene expression in such organelles is generally impaired, with multistep control occurring at transcriptional, post-transcriptional, and translational levels (Brosch et al. 2007; Kahlau and Bock 2008; Valkov et al. 2009). However, some transcripts, such as the transcript of the fatty acid biosynthesis gene, $a c c D$, displayed relatively high gene expression activity in potato tubers and in tomato and pepper fruits. All these studies have allowed the tentative identification of candidate regulatory sequences, which could potentially improve transgene expression in nongreen plastids (Kahlau and Bock 2008; Valkov et al. 2011).

Plastid genetic engineering has been extended to edible vaccine production, which could minimize the downstream processing costs and the risks associated with conventional vaccine production systems. In addition to added stability, correct disulfide bond formation in some therapeutic proteins is an absolute requirement for functional, biologically active molecules (Ludwig et al. 1985; Dertzbaugh and Cox 1998). Plastid genetic engineering would be an ideal system for the synthesis of sulfur-rich storage proteins, as protein disulfide isomerase, the enzyme responsible for the formation and breakage of disulfide bonds between cysteine residues within proteins, is known to be active in plastids (Kim and Mayfield 2002; Alergand et al. 2006). Another interesting feature of chloroplast transformation is the absence of a glycosylation pathway (Fernandez-San Millan et al. 2003; McCabe et al. 2008), which provides a unique opportunity to express therapeutic proteins free of glycosylation. Weeda et al. (2009) described the role of potato multicystatin (a multidomain Cys-type protease inhibitor), which facilitates the high accumulation of proteins in developing tubers and prevents the premature proteolysis of storage proteins in fully developed tubers by inhibiting Cys-type proteases (Weeda et al. 2009). These results could possibly provide a new opportunity to increase the foreign protein accumulation and storage in potato tubers. 
Oral delivery of vaccines, expressed in plant cells would reduce the costs associated with purification, processing, cold storage, transportation, and delivery, and would be more efficacious than injectable vaccines (Arlen et al. 2008). To date, most of the chloroplast-based vaccines have been produced in tobacco, but tobacco is not suitable for oral delivery of vaccines. Tomato and sweet peppers are two important Solanaceae crops, which are consumed as raw vegetables and have enormous scope for edible vaccine production. Green tomatoes accumulated the p24-Nef fusion protein to approximately $2.5 \%$ of the TSP; however, in red ripe tomatoes, expression of $\mathrm{p} 24-\mathrm{Nef}$ protein was hardly detectable when compared with leaves, thereby being similar to the situation in older tobacco and tomato leaves (Zhou et al. 2008). This is because most plastid genome-encoded genes involved in photosynthesis are downregulated in nonphotosynthetic tissues (Kahlau and Bock 2008). Chloroplast transformation of stay-green tomato/capsicum phenotypes for vaccine production would provide a solution for this. Alternatively, chloroplast transformation coupled with downregulation of "stay-green" $(S G R)$ genes, which are involved in regulation of plant senescence (Roca et al. 2006; Barry et al. 2008) would possibly facilitate the increased accumulation of vaccine peptides through delaying the fruit ripening or by allowing the coexistence of the chromoplasts and photosynthetically active chloroplast in the ripened fruits.

The use of inducible promoter systems, which trigger transgene expression upon induction by chemical or physical means, would avoid the deleterious effects caused by constitutive expression of transgenes in chloroplasts and would further ensure the security and control of production in GM plants. A nuclear-encoded ethanol-inducible plastidtargeted T7 RNA polymerase, which transcribes plastid transgenes from a $\mathrm{T} 7$ promoter system, has already been used for inducible expression of PHB in transplastomic tobacco (Lossl et al. 2005). A recently identified synthetic riboswitch, which functions as an efficient translational regulator of gene expression in plastids (Verhounig et al. 2010), could provide a novel tool for plastid genome engineering in the near future, as it facilitates the tightly regulated inducible expression of transgenes. Genomic approaches are being used to compare the expression of genes in chloroplasts, amyloplasts, and chromoplasts, with the aim of identifying regulatory sequences, which support high gene expression in non-green plastids. Candidate regulatory sequences that can potentially improve plastid (trans) gene expression in amyloplasts have already been identified (Valkov et al. 2009). Attempts were also made to improve the transformation efficiency, with the use of novel vectors containing species-specific flanking sequences for homologous recombination in the large single copy (LSC) region of the plastome (Scotti et al. 2011; Valkov et al.
2011). Experiments with vectors containing different promoters and terminators as well as the use of species-specific flanking and regulatory sequences have already been seen as promising. Further efforts should be made to develop tuberand fruit-specific plastid expression vectors for plastid transformation in non-green plant organs.

\section{Conclusion}

Considerable progress has been made in understanding the plastid transgene expression and in unraveling the potential of the technology for future biotechnological applications (Bock 2007; Verma et al. 2008; Bock and Warzecha 2010; Maliga and Bock 2011). A greater extent of foreign protein accumulation was achieved in transplastomic tobacco plants. A significant improvement in plastid transformation efficiency is likely to be of considerable value for future implementation in other Solanaceae crops. An efficient shoot regeneration system is the key to successful production of transplastomic plants, and with improved regeneration methods and genotypes with a high regeneration capacity, a further higher frequency of transplastomic plants could be achieved. Production of marker-free transplastomic plants would ease public concern and increase consumer preferences. Besides maximizing the expression of foreign proteins, careful optimization of the expression level is also required in order to minimize the adverse effects on plant system. The widespread use of plastid genetic engineering is still a long way off, especially in the case of expression of transgenes in non-green plastids. However, with the recent advances in gene expression technologies and plastid genomic studies, expression of the foreign in non-green organ plastids would be quite feasible in the near future.

Acknowledgement This paper resulted from the Konkuk University research support program (no. PJ008182), Rural Development Administration, Republic of Korea.

Conflict of interest The authors declare that they have no conflict of interest.

Open Access This article is distributed under the terms of the Creative Commons Attribution License which permits any use, distribution, and reproduction in any medium, provided the original author(s) and the source are credited.

\section{References}

Afroz A, Chaudhry Z, Rashid U, Ali GM, Nazir F, Iqbal J, Khan MR (2011) Enhanced resistance against bacterial wilt in transgenic tomato (Lycopersicon esculentum) lines expressing the Xa21 gene. Plant Cell Tiss Organ Cult 104:227-237 
Ahlert D, Ruf S, Bock R (2003) Plastid protein synthesis is required for plant development in tobacco. Proc Natl Acad Sci 100:1573015735

Alergand T, Peled-Zehavi H, Katz Y, Danon A (2006) The chloroplast protein disulfide isomerase RB60 reacts with a regulatory disulfide of the RNA-binding protein RB47. Plant Cell Physiol 47:540-548

Andrews JT, Whitney SM (2003) Manipulating ribulose bisphosphate carboxylase/oxygenase in the chloroplasts of higher plants. Arch Biochem Biophys 414:159-169

Apel W, Bock R (2009) Enhancement of carotenoid biosynthesis in transplastomic tomatoes by induced lycopene to provitamin A conversion. Plant Physiol 151:59-66

Apel W, Schulze WX, Bock R (2010) Identification of protein stability determinants in chloroplasts. Plant J 63:636-650

Arai Y, Shikanai T, Doi Y, Yoshida S, Yamaguchi I, Nakashita H (2004) Production of polyhydroxybutyrate by polycistronic expression of bacterial genes in tobacco plastid. Plant Cell Physiol 45:1176-1184

Arlen PA, Singleton M, Adamovicz JJ, Ding Y, Davoodi-Semiromi A, Daniell H (2008) Effective plague vaccination via oral delivery of plant cells expressing F1-V antigens in chloroplasts. Infect Immun 76:3640-3650

Bally J, Nadai M, Vitel M, Rolland A, Dumain R, Dubald M (2009) Plant physiological adaptations to the massive foreign protein synthesis occurring in recombinant chloroplasts. Plant Physiol 150:1474-1481

Barone P, Zhang XH, Widholm JM (2009) Tobacco plastid transformation using the feedback-insensitive anthranilate synthase $[\alpha]$ subunit of tobacco (ASA2) as a new selectable marker. J Exp Bot 60(11):3195-3202

Barry CS, McQuinn RP, Chung MY, Besuden A, Giovannoni JJ (2008) Amino acid substitutions in homologs of the staygreen protein are responsible for the green-flesh and chlorophyll retainer mutations of tomato and pepper. Plant Physiol 147(1):179-187

Bellucci M, De Marchis F, Mannucci R, Bock R, Arcioni S (2005) Cytoplasm and chloroplasts are not suitable subcellular locations for $\beta$-zein accumulation in transgenic plants. J Exp Bot 56:12051212

Berger IJ, Carraro DM, Bock R, Azevedo RA, Carrer H (2005) Cloning and sequence analysis of tomato cpDNA fragments: towards developing homologous chloroplast transformation vectors. Braz J Plant Physiol 17:239-245

Biggin P, Sansom M (1999) Interactions of $\alpha$-helices with lipid bilayers: a review of simulation studies. Biophys Chem 76:161183

Birch-Machin I, Newell CA, Hibberd JM, Gray JC (2004) Accumulation of rotavirus VP6 protein in chloroplasts of transplastomic tobacco is limited by protein stability. Plant Biotechnol J 2:261270

Bock R (2001) Transgenic plastids in basic research and plant. J Mol Biol 312:425-438

Bock R (2007) Plastid biotechnology: prospects for herbicide and insect resistance, metabolic engineering and molecular farming. Curr Opin Biotechnol 18:100-106

Bock R, Khan MS (2004) Taming plastids for a green future. Trends Biotechnol 22:311-318

Bock R, Maliga P (1995) In vivo testing of a tobacco plastid DNA segment for guide RNA function in psbL editing. Molec Gen Genet 247:439-443

Bock R, Warzecha H (2010) Solar-powered factories for new vaccines and antibiotics. Trends Biotechnol 28:246-252

Bohmert-Tatarev K, McAvoy S, Daughtry S, Peoples OP, Snell KD (2011) High levels of bioplastic are produced in fertile transplastomic tobacco plants engineered with a synthetic operon for the production of polyhydroxybutyrate. Plant Physiol 155 (4):1690-1708

Bornke F, Broer I (2010) Tailoring plant metabolism for the production of novel polymers and platform chemicals. Curr Opin Plant Biol 13:354-362

Boyhan D, Daniell H (2011) Low-cost production of proinsulin in tobacco and lettuce chloroplasts for injectable or oral delivery of functional insulin and C-peptide. Plant Biotechnol J 9:585-598. doi:10.1111/j.1467-7652.2010.00582.x

Boynton JE, Gillham NW, Harris EH, Hosler JP, Johnson AM, Jones AR, Randolph-Anderson BL, Robertson D, Klein TM, Shark KB et al (1988) Chloroplast transformation in Chlamydomonas with high velocity microprojectiles. Science 240:1534-1538

Brosch M, Krause K, Falk J, Krupinska K (2007) Analysis of gene expression in amyloplasts of potato tubers. Planta 227:91-99

Chakrabarti SK, Lutz KA, Lertwiriyawong B, Svab Z, Maliga P (2006) Expression of the cry9Aa2 B.t. gene in tobacco chloroplasts confers resistance to potato tuber moth. Transgenic Res 15:481488

Craig W, Lenzi P, Scotti N, De Palma M, Saggese P, Carbone V, McGrath-Curran N, Magee AM, Medgyesy P, Kavanagh TA, Dix PJ, Grillo S, Cardi T (2008) Transplastomic tobacco plants expressing a fatty acid desaturase gene exhibit altered fatty acid profiles and improved cold tolerance. Transgenic Res 17:769-782

Daniell H (2006) Production of biopharmaceuticals and vaccines in plants via the chloroplast genome. Biotechnol J 1:1071-1079

Daniell H (2007) Transgene containment by maternal inheritance: effective or elusive? Proc Natl Acad Sci 104(17):6879-6880

Daniell H, McFadden BA (1987) Uptake and expression of bacterial and cyanobacterial genes by isolated cucumber etioplasts. Proc Natl Acad Sci 84:6349-6353

Daniell H, Wiebe PO, Fernandez-San Millan A (2001a) Antibiotic-free chloroplast genetic engineering — an environmentally friendly approach. Trends Plant Sci 6(6):237-239

Daniell H, Lee SB, Panchal T, Wiebe PO (2001b) Expression of cholera toxin B subunit gene and assembly as functional oligomers in transgenic tobacco chloroplasts. J Mol Biol 311:1001-1009

Daniell H, Singh ND, Mason H, Streatfield SJ (2009) Plant-made vaccine antigens and biopharmaceuticals. Trends Plant Sci 14:669-679

Dauvillee D, Delhaye S, Gruyer S, Slomianny C, Moretz SE et al (2010) Engineering the chloroplast targeted malarial vaccine antigens in Chlamydomonas starch granules. PLoS One 5(12): e15424. doi:10.1371/journal.pone.0015424

Day A, Goldschmidt-Clermont M (2011) The chloroplast transformation toolbox: selectable markers and marker removal. Plant Biotechnol J 9:540-553

De Cosa B, Moar W, Lee SB, Miller M, Daniel H (2001) Overexpression of the $\mathrm{Bt}$ cry2Aa2 operon in chloroplasts leads to formation of insecticidal crystals. Nat Biotechnol 19:71-74

DeGray G, Rajasekaran K, Smith F, Sanford J, Daniell H (2001) Expression of an antimicrobial peptide via the chloroplast genome to control phytopathogenic bacteria and fungi. Plant Physiol 127:852-862

Demanèche S, Sanguin H, Poté J, Navarro E, Bernillon D, Mavingui P, Wildi W et al (2008) Antibiotic-resistant soil bacteria in transgenic plant fields. Proc Natl Acad Sci 105:3957-3962

Dertzbaugh MT, Cox LM (1998) The affinity of cholera toxin for $\mathrm{Ni}^{2+}$ ion. Protein Eng 11:557-581

Dhingra A, Portis AR, Daniell H (2004) Enhanced translation of a chloroplast-expressed $R b c S$ gene restores the subunit levels and photosynthesis in nuclear $R b c S$ antisense plants. Proc Natl Acad Sci 101:6315-6320

Dufourmantel N, Dubald M, Matringe M, Canard H, Garcon F, Job C, Kay E, Wisniewski JP, Ferullo JM, Pelissier B, Sailland A, Tissot 
G (2007) Generation and characterization of soybean and markerfree tobacco plastid transformants over- expressing a bacterial 4hydroxyphenylpyruvate dioxygenase which provides strong herbicide tolerance. Plant Biotechnol J 5:118-133

Eibl C, Zou Z, Beck A, Kim M, Mullet J, Koop HU (1999) In vivo analysis of plastid psbA, rbcL and rpl32 UTR elements by chloroplast transformation: tobacco plastid gene expression is controlled by modulation of transcript levels and translation efficiency. Plant J 19:333-345

Elghabi Z, Ruf S, Bock R (2011a) Biolistic co-transformation of the nuclear and plastid genomes. Plant J 67:941-948

Elghabi Z, Karcher D, Zhou F, Ruf S, Bock R (2011b) Optimization of the expression of the HIV fusion inhibitor. cyanovirin-N from the tobacco plastid genome. Plant Biotechnol J 9:599-608

Falk J, Brosch M, Schäfer A, Braun S, Krupinska K (2005) Characterization of transplastomic tobacco plants with a plastid localized barley 4-hydroxyphenylpyruvate dioxygenase. J Plant Physiology 162:738-742

Fernandez-San Millan A, Mingo-Castel A, Miller M, Daniell H (2003) A chloroplast transgenic approach to hyper-express and purify human serum albumin, a protein highly susceptible to proteolytic degradation. Plant Biotechnol J 1:71-79

Garcia I, Rodgers M, Pepin R, Hsieh TF, Matringe M (1999) Characterization and subcellular compartmentation of recombinant 4hydroxyphenylpyruvate dioxygenase from Arabidopsis in transgenic tobacco. Plant Physiol 119:1507-1516

Gargano D, Craig W, Lenzi P, Scotti N, Grillo S, Cardi T (2003) Stable plastid transformation of potato cv. Desiree with a gene involved in fatty acid desaturation. Proceedings of the XLVII Italian Society of Agricultural Genetics- SIGA Annual Congress, Verona, 24-27. September, 2003. ISBN 88-900622-4-X

Gargano D, Valkov V, Lenzi P, Scotti N, Grillo S, Cardi T (2005) Development and application of the plastid transformation technology in potato. Oral Communication Abstract, Proceedings of the XLIX Italian Society of Agricultural Genetics Annual Congress, Potenza, Italy - 12/15 September, 2005, ISBN 88-9006226-6

Genkov T, Meyer M, Griffiths H, Spreitzer RJ (2010) Functional hybrid Rubisco enzymes with plant small subunits and algal large subunits: engineered $r b c S$ cDNA for expression in Chlamydomonas. J Biol Chem 285:19833-19841

Girhepuje PV, Shinde GB (2011) Transgenic tomato plants expressing a wheat endochitinase gene demonstrate enhanced resistance to Fusarium oxysporum f. sp. Lycopersici. Plant Cell Tiss Organ Cult 105:243-251

Glick BR, Pasternak JJ (1998) Molecular biotechnology: principles and applications of recombinant DNA. American Society for Microbiology, Washington, DC

Goldschmidt-Clermont M (1991) Transgenic expression of aminoglycoside adenine transferase in the chloroplast: a selectable marker of site-directed transformation of Chlamydomonas. Nucleic Acids Res 19:4083-4089

Gorantala J, Grover S, Goel D, Rahi A, Magani SKJ, Chandra S, Bhatnagar R (2011) A plant based protective antigen [PA(dIV)] vaccine expressed in chloroplasts demonstrates protective immunity in mice against anthrax. Vaccine 29(27):4521-4533

Gray BN, Ahner BA, Hanson MR (2009) Extensive homologous recombination between introduced and native regulatory plastid DNA elements in transplastomic plants. Transgenic Res 18:559572

Gray BN, Yang H, Ahner BA, Hanson MR (2011) An efficient downstream box fusion allows high-level accumulation of active bacterial beta-glucosidase in tobacco chloroplasts. Plant Mol Biol 76 $(3-5): 345-355$
Guda C, Lee SB, Daniell H (2000) Stable expression of a biodegradable protein-based polymer in tobacco chloroplasts. Plant Cell Rep 19:257-262

Hagemann R (2002) Milestones in plastid genetics of higher plants. In: Esser K, Lüttge U, Beyschlag W, Hellwig F (eds) Progress in botany: genetics, physiology, ecology, vol 63. Springer, Heidelberg, pp 5-51

Haseloff J, Siemering KR (1998) The uses of GFP in plants. In: Chalfie M, Kain S (eds) Green fluorescence protein: strategies, applications and protocols. Wiley-Liss, New York, pp 191-220

Hennig A, Bonfig K, Roitsch T, Warzecha H (2007) Expression of the recombinant bacterial outer surface protein $\mathrm{A}$ in tobacco chloroplasts leads to thylakoid localization and loss of photosynthesis. FEBS J 274:5749-5758

Herrin DL, Nickelsen J (2004) Chloroplast RNA processing and stability. Photosynth Res 82:301-304

Hibberd JM, Linley PJ, Khan MS, Gray JC (1998) Transient expression of green fluorescent protein in various plastid types following microprojectile bombardment. Plant J 16:627-632

Houston ME Jr, Kondejevski L, Gough M, Fidai S, Hodges RS, Hancock R (1997) Influence of performed $\alpha$-helix and $\alpha$-helix induction on the activity of cationic antimicrobial peptides. J Pept Res 52:81-88

Huang CY, Ayliffe MA, Timmis JN (2003) Direct measurement of the transfer rate of chloroplast DNA into the nucleus. Nature 422:7276

Huhns M, Neumann K, Hausmann T, Ziegler K, Klemke F, Kahmann U, Staiger D, Lockau W, Pistorius EK, Broer I (2008) Plastid targeting strategies for cyanophycin synthetase to achieve highlevel polymer accumulation in Nicotiana tabacum. Plant Biotechnol J 6:321-336

Huhns M, Neumann K, Hausmann T, Klemke F, Lockau W, Kahmann $\mathrm{U}$ et al (2009) Tuber-specific cphA expression to enhance cyanophycin production in potatoes. Plant Biotechnol J 7(9):883-898

Iamtham S, Day A (2000) Removal of antibiotic resistance genes from transgenic tobacco plastids. Nat Biotechnol 18:1172-1176

Kahlau S, Bock R (2008) Plastid transcriptomics and translatomics of tomato fruit development and chloroplast-to-chromoplast differentiation: chromoplast gene expression largely serves the production of a single protein. Plant Cell 20:856-874

Kanevski I, Maliga P, Rhoades DF, Gutteridge S (1999) Plastome engineering of ribulose-1,5-bisphosphatecarboxylase/oxygenase in tobacco to form a sunflower large subunit and tobacco small subunit hybrid. Plant Physiol 119:133-141

Kim J, Mayfield SP (2002) The active site of the thioredoxin-like domain of chloroplast protein disulfide isomerase, RB60, catalyzes the redox-regulated binding of chloroplast poly(A)-binding protein, RB47, to the 5' untranslated region of psbA mRNA. Plant Cell Physiol 43(10):1238-1243

Kinney AJ (2006) Metabolic engineering in plants for human health and nutrition. Curr Opin Biotechnol 17:130-138

Klaus SMJ, Huang FC, Eibl C, Koop HU, Golds TJ (2003) Rapid and proven production of transplastomic tobacco plants by restoration of pigmentation and photosynthesis. Plant J 35(6):811-821

Klaus SM, Huang FC, Golds TJ, Koop HU (2004) Generation of marker-free plastid transformants using a transiently cointegrated selection gene. Nat Biotechnol 22:225-229

Knoblauch M, Hibberd JM, Gray JC, Van Bel AJE (1999) A galinstan expansion femtosyringe for microinjection of eukaryotic organelles and prokaryotes. Nat Biotechnol 17:906909

Kode V, Mudd EA, Iamtham S, Day A (2006) Isolation of precise plastid deletion mutants by homology-based excision: a resource for site-directed mutagenesis, multi-gene changes and highthroughput plastid transformation. Plant J 46:901-909 
Koehler RH, Zipfel WR, Webb WW, Hanson MR (1997) The green fluorescent protein as a marker to visualize plant mitochondria in vivo. Plant J 11:613-621

Koop HU, Steinmüller K, Wagner H, Rössler C, Eibl C, Sacher L (1996) Integration of foreign sequences into the tobacco plastome via polyethylene glycol-mediated protoplast transformation. Planta 199:193-201

Kooter JM, Matzke MA, Meyer P (1999) Listening to the silent genes: transgene silencing, gene regulation and pathogen control. Trends Plant Sci 4:340-347

Koya V, Moayeri M, Leppla SH, Daniell H (2005) Plant-based vaccine: mice immunized with chloroplast-derived anthrax protective antigen survive anthrax lethal toxin challenge. Infect Immun $73: 8266-8274$

Kuchuk N, Sytnyk K, Vasylenko M, Shakhovsky A, Komarnytsky I, Kushnir S, Gleba Y (2006) Genetic transformation of plastids of different Solanaceae species using tobacco cells as organelle hosts. Theor Appl Genet 113:519-527

Lee SB, Kwon HB, Kwon SJ, Park SC, Jeong MJ, Han SE, Byun MO, Daniell H (2003) Accumulation of trehalose within transgenic chloroplasts confers drought tolerance. Mol Breed 11:1-13

Lee M, Zhou Y, Lung R, Chye ML, Yip WK, Zee SY, Lam E (2006) Expression of viral capsid protein antigen against Epstein-Barr virus in plastids of Nicotiana tabacum cv. SR1. Biotechnol Bioeng 20:1129-1137

Lee SB, Li B, Jin S, Daniell H (2011) Expression and characterization of antimicrobial peptides Retrocyclin-101 and Protegrin-1 in chloroplasts to control viral and bacterial infections. Plant Biotechnol J 9:100-115

Lenzi P, Scotti N, Alagna F, Tornesello ML, Pompa A, Vitale A, De Stradis A, Monti L, Grillo S, Buonaguro FM, Maliga P, Cardi (2008) Translational fusion of chloroplast-expressed human papillomavirus type $16 \mathrm{~L} 1$ capsid protein enhances antigen accumulation in transplastomic tobacco. Transgenic Res 17(6):10911102

Li W, Ruf S, Bock R (2011) Chloramphenicol acetyltransferase as selectable marker for plastid transformation. Plant Mol Biol $76: 443-451$

Lloyd AH, Timmis JN (2011) The origin and characterization of new nuclear genes originating from a cytoplasmic organellar genome. Mol Biol Evol 28(7):2019-2028

Lopez AB, Van Eck J, Conlin BJ, Paolillo DJ, O’Neill J, Li L (2008) Effect of the cauliflower $\mathrm{Or}$ transgene on carotenoid accumulation and chromoplast formation in transgenic potato tubers. J Exp Bot 59:213-223

Lössl AG, Waheed MT (2011) Chloroplast-derived vaccines against human diseases: achievements, challenges and scopes. Plant Biotechnol J 9:527-539

Lossl A, Eibl C, Harloff HJ, Jung C, Koop HU (2003) Polyester synthesis in transplastomic tobacco (Nicotiana tabacum L.): significant contents of polyhydroxybutyrate are associated with growth reduction. Plant Cell Rep 21:891-899

Lossl A, Bohmert K, Harloff H, Eibl C, Mühlbauer S, Koop HU (2005) Inducible trans-activation of plastid transgenes: expression of the Reutropha phb operon in transplastomic tobacco. Plant Cell Physiol 46(9): 1462-1471

Lu S, Li L (2008) Carotenoid metabolism: biosynthesis, regulation, and beyond. J Integr Plant Biol 50:778-785

Ludwig DS, Holmes RK, Schoolnik GK (1985) Chemical and immunochemical studies on the receptor binding domain of cholera toxin B subunit. J Biol Chem 260:12528-12534

Lutz KA, Maliga P (2007) Construction of marker-free transplastomic plants. Curr Opin Biotechnol 18:107-114

Lutz KA, Knapp JE, Maliga P (2001) Expression of bar in the plastid genome confers herbicide resistance. Plant Physiol 125:1585-1590
Lutz KA, Azhagiri AK, Tungsuchat-Huang T, Maliga P (2007) A guide to choosing vectors for transformation of the plastid genome of higher plants. Plant Physiol 145:1201-1210

Madoka Y, Tomizawa KI, Miozoi J, Nishida I, Nagano Y, Sasaki Y (2002) Chloroplast transformation with modified accD operon increases acetyl-CoA carboxylase and causes extension of leaf longevity and increase in seed yield in tobacco. Plant Cell Physiol 43:1518-1525

Magee AM, Coyne S, Murphy D, Horvath EM, Medgyesy P, Kavanagh TA (2004) T7 RNA polymerase-directed expression of an antibody fragment transgene in plastids causes a semi-lethal pale-green seedling phenotype. Transgenic Res 13:325-337

Maliga P (2004) Plastid transformation in higher plants. Annu Rev Plant Physiology Plant Mol Biol 55:289-313

Maliga P, Bock R (2011) Plastid biotechnology: food, fuel, and medicine for the 21st century. Plant Physiol 155(4):1501-1510

Matsushima R, Hu Y, Toyoda K, Sodmergen SW (2008) The model plant Medicago truncatula exhibits biparental plastid inheritance. Plant Cell Physiol 49(1):81-91

McBride KE, Svab Z, Schaaf DJ, Hogan PS, Stalker DM, Maliga P (1995) Amplification of a chimeric Bacillus gene in chloroplasts leads to an extraordinary level of an insecticidal protein in tobacco. Bio/Technology 13:362-365

McCabe MS, Klaas M, Gonzalez-Rabade N, Poage M, Badillo-Corona JA, Zhou F, Karcher D, Bock R, Gray JC, Dix PJ (2008) Plastid transformation of high-biomass tobacco variety Maryland Mammoth for production of human immunodeficiency virus type 1 (HIV-1) p24 antigen. Plant Biotechnol J 6:914-929

Meiyalaghan S, Pringle JM, Barrell PJ, Jacobs JME, Conner AJ (2010) Pyramiding transgenes for potato tuber moth resistance in potato. Plant Biotechnol Rep 4:293-301

Meyer L, Serek M, Winkelmann T (2009) Protoplast isolation and plant regeneration of different genotypes of Petunia and Calibrachoa. Plant Cell Tiss Organ Cult 99:27-34

Molina A, Veramendi J (2009) High stability of recombinant proteins expressed in tobacco chloroplasts. Open Biotechnol J 3:67-72

Morgenfeld M, Segretin ME, Wirth S, Lentz E, Zelada A, Mentaberry A, Gissmann L, Bravo-Almonacid F (2009) Potato virus X coat protein fusion to human papillomavirus $16 \mathrm{E} 7$ oncoprotein enhance antigen stability and accumulation in tobacco chloroplast. Mol Biotechnol 43:243-249

Nakashita H, Arai Y, Shikanai T, Doi Y, Yamaguchi I (2001) Introduction of bacterial metabolism into higher plants by polycistronic transgene expression. Biosci Biotechnol Biochem 65:1688-1691

Neumann K, Stephan DP, Ziegler K, Hühns M, Broer I, Lockau W, Pistorius EK (2005) Production of cyanophycin, a suitable source for the biodegradable polymer polyaspartate, in transgenic plants. Plant Biotechnol J 3:249-258

Nguyen TT, Nugent G, Cardi T, Dix PJ (2005) Generation of homoplasmic plastid transformants of a commercial cultivar of potato (Solanum tuberosum L.). Plant Sci 168:1495-1500

Nugent JM, Joyce SM (2005) Producing human therapeutic proteins in plastids. Curr Pharm Des 11:2459-2470

Nugent GD, Ten Have M, van der Gulik A, Dix PJ, Uijtewaal BA, Mordhorst AP (2005) Plastid transformants of tomato selected using mutations affecting ribosome structure. Plant Cell Rep 24:341-349

O'Neill C, Horvath GV, Horvath E, Dix PJ, Medgyesy P (1993) Chloroplast transformation in plants: polyethylene glycol (PEG) treatment of protoplasts is an alternative to biolistic delivery systems. Plant J 3:729-738

Oey M, Lohse M, Kreikemeyer B, Bock R (2009) Exhaustion of the chloroplast protein synthesis capacity by massive expression of a highly stable protein antibiotic. Plant J 57:436-445 
Parry MAJ, Madgwick PJ, Carvalho JFC, Andralojc PJ (2007) Prospects for increasing photosynthesis by overcoming the limitations of Rubisco. J Agric Sci 145:31-43

Penna S, Sagi L, Swennen R (2002) Positive selectable marker genes for routine plant transformation. In Vitro Cell Dev Biol-Plant 38:125-128

Petersen K, Bock R (2011) High-level expression of a suite of thermostable cell wall-degrading enzymes from the chloroplast genome. Plant Mol Biol 76:311-321

Petersen K, Schöttler MA, Karcher D, Thiele W, Bock R (2011) Elimination of a group II intron from a plastid gene causes a mutant phenotype. Nucl Acids Res 39(12):5181-5192

Poage M, Martret L, Jansen MAK, Nugent GD, Dix PJ (2011) Modification of reactive oxygen species scavenging capacity of chloroplasts through plastid transformation. Plant Mol Biol 76:371-384

Pogson BJ, Albrecht V (2011) Genetic dissection of chloroplast biogenesis and development: an overview. Plant Physiol 155 (4): $1545-1551$

Quesada-Vargas T, Ruiz ON, Daniell H (2005) Characterization of heterologous multigene operons in transgenic chloroplasts. Transcription, processing, and translation. Plant Physiol 138:17461762

Raines CA (2006) Transgenic approaches to manipulate the environmental responses of the $\mathrm{C} 3$ carbon fixation cycle. Plant Cell Environ 29:331-339

Rathinasabapathi B, McCue KF, Gage DA, Hanson AD (1994) Metabolic engineering of glycine betaine synthesis: plant betaine aldehyde dehydrogenases lacking typical transit peptides are targeted to tobacco chloroplasts where they confer betaine aldehyde resistance. Planta 193:155-162

Robinson SP, Jones GP (1986) Accumulation of glycine betaine in chloroplasts provides osmotic adjustment during salt stress. Aust J Plant Physiology 13:659-668

Roca M, Hornero-Méndez D, Gandul-Rojas B, Mínguez-Mosquera MI (2006) Stay-Green phenotype slows the carotenogenic process in Capsicum annuum (L.) Fruits. J Agric Food Chem 54(23):87828787

Rogalski M, Carrer H (2011) Engineering plastid fatty acid biosynthesis to improve food quality and biofuel production in higher plants. Plant Biotechnol J 9(5):554-564

Rogalski M, Ruf S, Bock R (2006) Tobacco plastid ribosomal protein S18 is essential for cell survival. Nucleic Acids Res 34:45374545

Ruf S, Hermann M, Berger I, Carrer H, Bock R (2001) Stable genetic transformation of tomato plastids and expression of a foreign protein in fruit. Nat Biotechnol 19:870-875

Ruf S, Karcher D, Bock R (2007) Determining the transgene containment level provided by chloroplast transformation. Proc Natl Acad Sci 104(17):6998-7002

Ruhlman T, Ahangari R, Devine A, Samsam M, Daniell H (2007) Expression of cholera toxin B-proinsulin fusion protein in lettuce and tobacco chloroplasts - oral administration protects against development of insulitis in non-obese diabetic mice. Plant Biotechnol J 5:495-510

Ruhlman T, Verma D, Samson N, Daniell H (2010) The role of heterologous chloroplast sequence elements in transgene integration and expression. Plant Physiol 152:2088-2104

Ruiz ON, Daniell H (2005) Engineering cytoplasmic male sterility via the chloroplast genome by expression of $\beta$-ketothiolase. Plant Physiol 138(3):1232-1246

Sanford JC, Smith FD, Russell JA (1993) Optimizing the biolistic process for different biological applications. Methods Enzymol 217:483-509

Schädlich L, Senger T, Gerlach B, Mücke N, Klein C, Bravo IG, Müller M, Gissmann L (2009) Analysis of modified human papillomavirus type $16 \mathrm{~L} 1$ capsomeres: the ability to assemble into larger particles correlates with higher immunogenicity. J Virol 83:7690-7705

Scheller J, Conrad U (2005) Plant-based material, protein and biodegradable plastic. Curr Opin Plant Biol 8:188-196

Schiraldi C, DiLernia I, DeRosa M (2002) Trehalose production: exploiting novel approaches. Trends Biotechnol 20:420-425

Scotti N, Valkov VT, Cardi T (2011) Improvement of plastid transformation efficiency in potato by using vectors with homologous flanking sequences. GM Crops 2(2):89-91

Segretin ME, Lentz EM, Wirth SA, Morgenfeld MM, BravoAlmonacid FF (2011) Transformation of Solanum tuberosum plastids allows high expression levels of $\beta$-glucuronidase both in leaves and microtubers developed in vitro. Planta. doi:10.1007/ s00425-011-1541-6

Sheppard AE, Madesis P, Lloyd AH, Day A, Ayliffe MA, Timmis JN (2011) Introducing an RNA editing requirement into a plastidlocalised transgene reduces but does not eliminate functional gene transfer to the nucleus. Plant Mol Bio 1 76:299-309

Sidorov VA, Kasten D, Pang SZ, Hajdukiewicz PTJ, Staub JM, Nehra NS (1999) Stable chloroplast transformation in potato: use of green fluorescent protein as a plastid marker. Plant J 19:209-216

Sigeno A, Hayashi S, Terachi T, Yamagishi H (2009) Introduction of transformed chloroplasts from tobacco into petunia by asymmetric cell fusion. Plant Cell Rep 28:1633-1640

Sim JS, Pak HK, Kim DS, Lee SB, Kim YH, Hahn BS (2009) Expression and characterization of synthetic heat-labile enterotoxin $\mathrm{b}$ subunit and hemagglutinin-neuraminidase-neutralizing epitope fusion protein in Escherichia coli and tobacco chloroplasts. Plant Mol Biol Rep 27:388-399

Singh AK, Verma SS, Bansal KC (2010) Plastid transformation in eggplant (Solanum melongena L.). Transgenic Res 19:113-119

Soria-Guerra RE, Alpuche-Solis AG, Rosales-Mendoza S, MorenoFierros L, Bendik EM, Martinez-Gonzalez L, Korban SS (2009) Expression of a multi-epitope DPT fusion protein in transplastomic tobacco plants retains both antigenicity and immunogenicity of all three components of the functional oligomer. Planta 229:1293-1302

Spreitzer RJ, Salvucci ME (2002) Rubisco: structure, regulatory interactions, and possibilities for a better enzyme. Annu Rev Plant Biol 53:449-475

Staub JM, Maliga P (1995) Expression of a chimeric uidA gene indicates that polycistronic mRNAs are efficiently translated in tobacco plastids. Plant J 7:845-848

Staub JM, Garcia B, Graves J, Hajdukiewicz PT, Hunter P, Nehra N, Paradkar V, Schlittler M, Carroll JA, Spatola L, Ward D, Ye G, Russell DA (2000) High-yield production of a human therapeutic protein in tobacco chloroplasts. Nat Biotechnol $18: 333-338$

Stegemann S, Bock R (2006) Experimental reconstruction of functional gene transfer from the tobacco plastid genome to the nucleus. Plant Cell 18:2869-2878

Stegemann S, Hartmann S, Ruf S, Bock R (2003) High-frequency gene transfer from the chloroplast genome to the nucleus. Proc Natl Acad Sci 100(15):8828-8833

Svab Z, Maliga P (1991) Mutation proximal to the tRNA binding region of the Nicotiana plastid 16S rRNA confers resistance to spectinomycin. Mol Gen Genet 228:316-319

Svab Z, Maliga P (1993) High frequency plastid transformation in tobacco by selection for a chimeric aadA gene. Proc Natl Acad Sci 90:913-917

Svab Z, Maliga P (2007) Exceptional transmission of plastids and mitochondria from the transplastomic pollen parent and its impact on transgene containment. Proc Natl Acad Sci 104:7003-7008

Svab Z, Hajdukiewicz P, Maliga P (1990) Stable transformation of plastids in higher plants. Proc Natl Acad Sci 87:8526-8530 
Talianova M, Janousek B (2011) What can we learn from tobacco and other Solanaceae about horizontal DNA transfer? Am J Bot 98 (8):1231-1242

Tregoning JS, Nixon P, Kuroda H, Svab Z, Clare S, Bowe F, Fairweather N, Ytterberg J, van Wijk KJ, Dougan G, Maliga P (2003) Expression of tetanus toxin fragment $\mathrm{C}$ in tobacco chloroplasts. Nucleic Acids Res 31:1174-1179

Upadhyaya CP, Nookaraju A, Gururani MA, Upadhyaya DC, Kim DH, Chun SC, Park SW (2010) An update on the progress towards the development of marker-free transgenic plants. Botanical Studies 51(3):277-292

Valkov T, Scotti N, Kahlau S, MacLean D, Grillo S, Gray JC, Bock R, Cardi T (2009) Genome-wide analysis of plastid gene expression in potato leaf chloroplasts and tuber amyloplasts: transcriptional and posttranscriptional control. Plant Physiol 150:2030-2044

Valkov VT, Gargano D, Manna C, Formisano G, Dix PJ, Gray JC, Scotti N, Cardi T (2011) High efficiency plastid transformation in potato and regulation of transgene expression in leaves and tubers by alternative 5' and 3' regulatory sequences. Transgenic Res 20:137-151

Van Beilen JB (2008) Transgenic plant factories for the production of biopolymers and platform chemicals. Biofuels Bioprod Biorefining 2(3):215-228

van Bel AJE, Hibberd J, Prüfer D, Knoblauch M (2001) Novel approach in plastid transformation. Curr Opin Biotechnol 12:144-149

van Wijk KJ, Baginsky S (2011) Plastid proteomics in higher plants: current state and future goals. Plant Physiol 155(4):1578-1588

Verhounig A, Karcher D, Bock R (2010) Inducible gene expression from the plastid genome by a synthetic riboswitch. Proc Natl Acad Sci 107:6204-6209

Verma D, Daniell H (2007) Chloroplast vector systems for biotechnology applications. Plant Physiol 145:1129-1143

Verma D, Samson NP, Koya V, Daniell H (2008) A protocol for expression of foreign genes in chloroplasts. Nat Protoc 3:739-758

Von Caemmerer S, Evans JR (2010) Enhancing C3 photosynthesis. Plant Physiol 154:589-592

Waheed MT, Thönes N, Müller M, Hassan SW, Razavi NM, Lössl E, Kaul HP, Lössl AG (2011) Transplastomic expression of a modified human papillomavirus L1 protein leading to the assembly of capsomeres in tobacco: a step towards cost-effective secondgeneration vaccines. Transgenic Res 20:271-282

Waterer D, Benning NT, Wu G, Luo X, Liu X, Gusta M, McHughen A, Gusta LV (2010) Evaluation of abiotic stress tolerance of genetically modified potatoes (Solanum tuberosum cv. Desiree). Mol Breed 25:527-540

Watson J, Koya V, Leppla SH, Daniell H (2004) Expression of Bacillus anthracis protective antigen in transgenic chloroplasts of tobacco, a non-food/feed crop. Vaccine 22:4374-4384

Weeda SM, Kumar GNM, Knowles NR (2009) Developmentally linked changes in proteases and protease inhibitors suggest a role for potato multicystatin in regulating protein content of potato tubers. Planta 230:73-84
Wei Z, Liu Y, Lin C, Wang Y, Cai Q, Dong Y, Xing S (2011) Transformation of alfalfa chloroplasts and expression of green fluorescent protein in a forage crop. Biotechnol Lett 33:24872494. doi:10.1007/s10529-011-0709-2

Whitney SM, Andrews TJ (2001) The gene for the ribulose-1,5bisphosphate carboxylase/oxygenase (Rubisco) small subunit relocated to the plastid genome of tobacco directs the synthesis of small subunits that assemble into Rubisco. Plant Cell 13:193205

Whitney SM, Sharwood RE (2008) Construction of a tobacco master line to improve Rubisco engineering in chloroplasts. J Exp Bot 59:1909-1921

Whitney SM, Houtz RL, Alonso H (2011) Advancing our understanding and capacity to engineer nature's $\mathrm{CO}_{2}$-sequestering enzyme, Rubisco. Plant Physiol 155(1):27-35

Wurbs D, Ruf S, Bock R (2007) Contained metabolic engineering in tomatoes by expression of carotenoid biosynthesis genes from the plastid genome. Plant J 49:276-288

Xia XX, Qiana ZG, Kib CS, Park YH, Kaplan DL, Lee SY (2010) Native-sized recombinant spider silk protein produced in metabolically engineered Escherichia coli results in a strong fiber. Proc Natl Acad Sci 107:14059-14063

Ye GN, Hajdukiewicz PT, Broyles D, Rodriguez D, Xu CW, Nehra N, Staub JM (2001) Plastid-expressed 5-enolpyruvylshikimate-3phosphate synthase genes provide high level glyphosate tolerance in tobacco. Plant J 25:261-270

Ye GN, Colburn SM, Xu CW, Hajdukiewicz PTJ, Staub JM (2003) Persistence of unselected transgenic DNA during a plastid transformation and segregation approach to herbicide resistance. Plant Physiol 133:402-410

Zhang XH, Ewy RG, Widholm JM, Portis AR Jr (2002) Complementation of the nuclear antisense rbcS-induced photosynthesis deficiency by introducing an $r b c S$ gene into the tobacco plastid genome. Plant Cell Physiol 43:1302-1313

Zhang J, Tan W, Yang XH, Zhang HX (2008) Plastid-expressed choline monooxygenase gene improves salt and drought tolerance through accumulation of glycine betaine in tobacco. Plant Cell Rep 27:1113-1124

Zhang XH, Webb J, Huang YH, Lin L, Tang RS, Liu A (2011) Hybrid Rubisco of tomato large subunits and tobacco small subunits is functional in tobacco plants. Plant Sci 180:480-488

Zhou F, Karcher D, Bock R (2007) Identification of a plastid intercistronic expression element (IEE) facilitating the expression of stable translatable monocistronic mRNAs from operons. Plant $\mathrm{J}$ 52:961-972

Zhou F, Badillo-Corona JA, Karcher D, Gonzalez-Rabade N, Piepenburg K, Borchers AMI, Maloney AP, Kavanagh TA, Gray JC, Bock R (2008) High-level expression of human immunodeficiency virus antigens from the tobacco and tomato plastid genomes. Plant Biotechnol J 6:897-913

Zubko MK, Zubko EI, Zuilen K, Meyer P, Day A (2004) Stable transformation of petunia plastids. Transgenic Res 13:523-530 